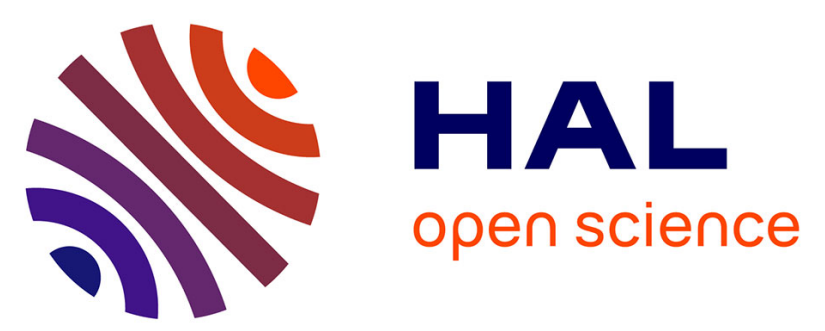

\title{
First direct evidence of inter-partner hydride/deuteride exchanges for stored sodiated arginine/fructose-6-phosphate complex anions within salt-solvated structures
}

Ekaterina Darii, Yves Gimbert, Sandra Alves, Annelaure Damont, Alain Perret, Amina S Woods, François Fenaille, Jean-Claude Tabet

\section{To cite this version:}

Ekaterina Darii, Yves Gimbert, Sandra Alves, Annelaure Damont, Alain Perret, et al.. First direct evidence of inter-partner hydride/deuteride exchanges for stored sodiated arginine/fructose-6-phosphate complex anions within salt-solvated structures. Journal of The American Society for Mass Spectrometry, In press, 32 (6), pp.1424-1440. 10.1021/jasms.1c00040 . hal-03242854

\section{HAL Id: hal-03242854 \\ https://hal.science/hal-03242854}

Submitted on 31 May 2021

HAL is a multi-disciplinary open access archive for the deposit and dissemination of scientific research documents, whether they are published or not. The documents may come from teaching and research institutions in France or abroad, or from public or private research centers.
L'archive ouverte pluridisciplinaire HAL, est destinée au dépôt et à la diffusion de documents scientifiques de niveau recherche, publiés ou non, émanant des établissements d'enseignement et de recherche français ou étrangers, des laboratoires publics ou privés. 


\title{
First direct evidence of inter-partner hydride/deuteride exchanges for stored sodiated arginine/fructose-6-phosphate complex anions within salt-solvated structures
}

\author{
Ekaterina Darii ${ }^{1 *}$, Yves Gimbert ${ }^{2,3}$, Sandra Alves ${ }^{3}$, Annelaure Damont ${ }^{4}$, Alain Perret ${ }^{1}$, Amina S. \\ Woods ${ }^{5,6}$, François Fenaille ${ }^{4}$, and Jean-Claude Tabet ${ }^{3,4^{*}}$
}

${ }^{1}$ Génomique Métabolique, Genoscope, Institut François Jacob, CEA, CNRS, Univ Evry, Université ParisSaclay, 91057 Evry, France

2Département de Chimie Moléculaire, UMR CNRS 5250, Université Grenoble Alpes, 38058 Grenoble, France

${ }^{3}$ Sorbonne Université, Faculté des Sciences et de l'Ingénierie, Institut Parisien de Chimie Moléculaire (IPCM), F-75005 Paris, France

${ }^{4}$ Université Paris-Saclay, CEA, INRAE, Département Médicaments et Technologies pour la Santé (DMTS), MetaboHUB, F-91191 Gif sur Yvette, France

${ }^{5}$ NIDA IRP, NIH Structural Biology Unit Cellular Neurobiology Branch, 333 Cassell Drive, Baltimore, Maryland 21224, United States

${ }^{6}$ The Johns Hopkins University School of Medicine, Pharmacology and Molecular Sciences, Baltimore, MD 21205

${ }^{*}$ Corresponding authors: Ekaterina Darii and Jean-Claude Tabet

Short title: $\mathrm{H}^{\top} / \mathrm{D}^{-}$exchanges in non-covalent salt anions 


\begin{abstract}
Mass spectrometric investigations of non-covalent binding between low molecular weight compounds revealed the existence of gas phase (GP) noncovalent complex (NCC) ions involving zwitterionic structures. ESI MS is used to prove the formation of stable sodiated NCC anions between fructose (F6P) and arginine (R) moieties. Theoretical calculations indicate a folded solvated salt (i.e., sodiated carboxylate interacting with phosphate) rather than a charge-solvated form. Under standard $\mathrm{CID}$ conditions, $[(\mathrm{F} 6 \mathrm{P}+\mathrm{R}-\mathrm{H}+\mathrm{Na})-\mathrm{H}]^{-}$competitively forms two major product ions (PIs) through partner splitting [( $\mathrm{R}-\mathrm{H}+\mathrm{Na})$ loss] and charge-induced cross-ring cleavage while preserving the noncovalent interactions (noncovalent product ions (NCPIs)).

MS/MS experiments combined with in-solution proton/deuteron exchanges (HDXs) demonstrated an unexpected labeling of PIs i.e., a correlated D-enrichment/D-depletion. Increase in activation time up to $3000 \mathrm{~ms}$ favors such processes when limited to two H/D exchanges. These results are rationalized by inter-partner hydride/deuteride exchanges $(\langle\mathrm{HDX}\rangle)$ through stepwise isomerization/dissociation of sodiated NCC-d11 anions. In addition, the D-enrichment/D-depletion discrepancy is further explained by back HDX with residual water in LTQ (selective for the isotopologue NCPIs as shown by PI relaxation experiments). Each isotopologue leads to only one back HDX unlike multiple HDXs generally observed in GP. This behavior shows that NCPIs are zwitterions with charges solvated by a single water molecule, thus generating a back HDX through a relay mechanism, which quenches the charges and prevents further back HDX. By estimating back HDX impact on Ddepletion, the inter-partner $<H D X>$ complementarity was thus illustrated. This is the first description of interpartner $<$ HDX >and selective back HDX validating salt solvated structures.
\end{abstract}




\section{Introduction}

Non-covalent complexes (NCC) are generated in both liquid and gas phase conditions, by a variety of chemical interactions, such as electrostatic (e.g. ionic or hydrogen bonding) or hydrophobic interactions. ${ }^{1-9}$ In living organisms, non-covalent interactions between biomolecules are the basis of molecular recognition mechanisms essential for regulation of biological processes. ${ }^{10}$ Such mechanisms often involve interactions between reactive groups of the different partners, e.g. guanidinium group of arginine and phosphate group of fructose phosphate. ${ }^{11-16}$ Mass spectrometry (MS) with its high resolution and sensitivity is the ultimate tool to investigate and understand these mechanisms. When using electrospray ionization mass spectrometry (ESI MS) to analyze mixtures of low molecular weight compounds, formation of NCC between guanidium and phosphate groups of the interacting molecules is often observed in the gas phase (GP). ${ }^{4}$

The nature and strengths of electrostatic interactions formed between small poly-functional compounds in GP (i.e., after ionization), are mainly determined by their respective functional groups. ${ }^{17,18}$ The increased stability of electrostatic interactions in the absence of solvent favors retention of the native molecular structures..$^{17,19,20}$ However, charge location and conformation of the non-covalent complex ions (NCC) may depend on the ESI source conditions (e.g. nature of solvent and buffer, source temperature and desolvation conditions). ${ }^{21-24}$ Gas phase studies of NCC ions very often consider small size partners as the canonical structures, forming hydrogen bonded (HB) systems in the gas phase. The corresponding ionized NCC species are thus ion/neutral complexes described as two neutrals or two anions solvating a proton for positive or negative mode, respectively. ${ }^{25-27}$ These forms can be relatively stable when the interacting partners bear chemical functions with close GP basicity or acidity..$^{25,26,28,29}$ Dissociation of such protonated (or deprotonated) HB multimers, under low energy collision conditions proceed through HB cleavages resulting in competitively charged partners with relative abundances depending on their relative GP basicity (or acidity) properties (basis of the kinetic method. ${ }^{28,29}$

Alternatively, one of the interacting partners may exist in zwitterionic (ZW) form and can be complexed with another protonated (or deprotonated) partner within the canonical form. ${ }^{30,31}$ Such NCC ions are maintained by ionic interactions such as salt bridge (SB) or salt (SA) bonding, ${ }^{17,32-35}$ as it occurs in NCC systems involving peptide/phosphate (or drug), ${ }^{36,37}$ or DNA/peptide (or drug). ${ }^{38-40}$ In these particular cases, ionic interactions are strengthened when involving strong basic (or acidic) interacting partners ${ }^{17-19}$ and then, under low energy collision conditions, the resulting NCC ions lead to charge-induced covalent bond (CB) cleavage while preserving non-covalent ionic interactions. ${ }^{38,40-}$

${ }^{42}$ Consequently, HB and ionic forms can be theoretically distinguished according to their respective fragmentation patterns. ${ }^{43}$ 
We recently studied, under resonant excitation conditions (collision induced dissociation: CID), the behavior of ESI-generated arginine/hexose-phosphate (HexP) complexes as $[(\mathrm{HexP}+\mathrm{R}-\mathrm{H}+\mathrm{Na})-\mathrm{H}]^{-}{ }^{41}$ as a system representative of biologically relevant protein's arginine complexes. ${ }^{11,12}$ Complementary investigations combining CID experiments and quantum calculations revealed the existence of two sodiated NCC structures: (i) the HB form with the remote salt group and (ii) the form with the arginine salt group solvated by the phosphate group of $[\mathrm{HexP}-\mathrm{H}]^{-}$(i.e., solvated salt, SSA). The HB form dissociates exclusively by partner splitting, while in the case of SSA form, the free negative charge promoted cross-ring cleavage(s) of hexose.

Otherwise, in-solution hydrogen/deuterium exchange (HDX) represents a useful tool to investigate structure and fragmentation patterns of complex ions. This method has been primarily introduced to deduce the mobile proton number in small size molecules in solution or in the gas phase for the study of even-electron molecular species. ${ }^{44-48}$ Such proton/deuteron exchanges (HDX) are also currently applied to study non-covalent system conformations in biomolecules, ${ }^{49-52}$ and/or to highlight gas phase fragmentation patterns. ${ }^{53-55}$ In the present work, HDX approach was applied to explore the HB and SSA forms of sodiated NCC anions formed between fructose-6-phosphate (F6P) and arginine (R). Fragmentation patterns of deuterium-labeled sodiated NCC anions after complete in-solution mobile proton exchanges were studied using the CID as well as and HCD modes (higher energy dissociation, a non-resonant excitation mode $)^{56}$ under variable excitation energy conditions and excitation times. The investigated fragmentation patterns demonstrated for the first time the existence of inter-partner hydride/deuteride exchanges during the dissociation of the sodiated NCC anions. Such unexpected processes are proven by the production of labeled product ions, one with unexpected D-enrichment and another with D-depletion. These phenomena were exacerbated by longer excitation times and weaker resonant excitation conditions. These experimental results also give evidences that the studied sodiated NCC exist mostly within ionic structures. 


\section{Material and methods}

\section{Chemicals}

Fructose-6-phosphate (F6P) and arginine (R) were purchased from Sigma-Aldrich (Saint-Quentin Fallavier, France). To conduct in-solution H/D exchange experiments, stock solutions of F6P and R mixture were prepared in $\mathrm{D}_{2} \mathrm{O}$ (Aldrich, Saint-Quentin Fallavier, France) and then used at a final concentration of $100 \mu \mathrm{M}$.

\section{$\underline{\text { Quantum calculations }}$}

All calculations were performed using the Gaussian 09 (revision D.01) software package (Gaussian Inc. Wallingford CT 2009). ${ }^{57}$ Optimization of geometries, frequency and single point energy calculations were done using the B3LYP functional with the $6-31+G^{* *}$ basis set. ${ }^{58,59}$

\section{Mass spectrometry}

Mass spectrometry analyses were performed using a Velos/Orbitrap Elite mass spectrometer (Thermo Fisher Scientific, Courtaboeuf, France) equipped with an ESI source. The negative ion mass spectra and product ion spectra were recorded using high resolution Orbitrap detection (FT/MS) to distinguish all isobaric isotopologues containing more or less incorporated deuterium and eventually

${ }^{13} \mathrm{C}$ isotopologues. A Fusion tribrid instrument (Thermo Fisher Scientific, Courtaboeuf, France) was also used to obtain higher sensitivity in sequential $M S^{n}$ experiments on the $\left[\mathrm{F}_{\mathrm{d}} \mathrm{P}_{\mathrm{d} 6}+\mathrm{R}_{\mathrm{d} 7}-\mathrm{D}\right]^{-} \mathrm{NCC}$ anions exhibiting poor stability during the isolation step in the ion trap (see Figure $\mathbf{5 4}$ ).

The mixture of F6P and $\mathrm{R}$ dissolved in $\mathrm{D}_{2} \mathrm{O}$ at a final concentration of $100 \mu \mathrm{M}$ was directly infused at 7 $\mu \mathrm{L} / \mathrm{min}$ using a syringe pump. Ion spray (IS) was set at $-3.5 \mathrm{kV}, \mathrm{m} / \mathrm{z}$ range was set from $50 \mathrm{~m} / \mathrm{z}$ to $1000 \mathrm{~m} / \mathrm{z}$. Sheath gas and auxiliary gas flow rates were set at 10 a.u. and 2 a.u. (arbitrary units), respectively. The peaks displayed in mass spectra and product ion spectra were annotated with experimentally accurate $\mathrm{m} / \mathrm{z}$ values. However, for the sake of simplicity only nominal $\mathrm{m} / \mathrm{z}$ values were reported in the text of this paper. Theoretical peak resolution for FT/MS detection (VelosPRO/Orbitrap Elite) was set at 120,000 at m/z 400 (full width at half maximum, FWHM).

Isolation $\mathrm{m} / \mathrm{z}$ width was set at $1.2 \mathrm{~m} / \mathrm{z}$ for all sequential MS/MS (using CID and HCD modes, ${ }^{56,60}$ see S1 in Supporting Information) and sequential $\mathrm{MS}^{3}$ experiments (using CID). For precursor ion excitation and storage under CID conditions (corresponding to resonant CID mode) in the linear trap device, the $q_{z}$ stability parameter value (as ActQ value) was set at 0.25 (resulting in a low mass cut-off (LMCO) of $28 \%$ of precursor ion $\mathrm{m} / \mathrm{z}$ value) in addition some experiments were also performed at 0.15 for favoring the detection of lower mass product ions. In addition, ActQ lowering allows 
reducing the maximum of kinetic energy of precursor ions under resonant excitation (see S1 in Supporting Information). ${ }^{61-63}$

Energy resolved mass spectrometry (ERMS) experiments ${ }^{28,64,65}$ were done under standard conditions, using activation time (ActT) at $10 \mathrm{~ms}$ and $0.1 \mathrm{~ms}$ for CID and HCD modes, respectively (S2 in Supporting Information). Collision energy (expressed as normalized collision energy, NCE) ${ }^{66}$ was varied from $0 \%$ to $25 \%$ for CID, and from $0 \%$ to $100 \%$ for HCD mode. These NCE value scales were chosen so that the ERMS breakdown curves show significant variations in the relative abundances of the precursor and product ions. Complementary MS/MS and ERMS experiments were also performed by changing ActT and/or ActQ values while fixing other excitation parameters (Figure S1 in Supporting Information). The excitation parameters are systematically reported in Figure captions.

\section{$\underline{\text { Notations and nomenclature }}$}

Deprotonation can occur at different acidic positions within the (labeled) sodiated NCC anions. By analogy with a protomer, different isomeric anions were herein named "deprotomers". The protomer ions refer to the ion distribution resulting from competitive protonation at different basic sites of a polyfunctional molecule or from the proton migration (prototropy). ${ }^{67,68}$ Prototropy can also occur for anions, as one deprotomer can isomerize into another by proton migration. The used notations are made in accordance with the IUPAC recommendations. ${ }^{69}$ For the MS signal annotation, the recent proposal made for describing ion species will be followed for the ionized salts, ${ }^{70}$ for example, the sodiated NCC anions named $[(\mathrm{F} 6 \mathrm{P}+\mathrm{R}-\mathrm{H}+\mathrm{Na})-\mathrm{H}]^{-}$. Such annotation reflects the possible populations of structures i.e., HB and SSA forms (Scheme 1). Note that SSA form can be canonical (i.e., $\mathrm{SSA}_{\mathrm{can}}$ ) and zwitterionic (i.e., $\mathrm{SSA}_{\mathrm{zw}}$ ).

Next, for H/D exchange experiments, HDX acronym is currently used to indicate the exchanges between mobilizable protons $\left(\mathrm{H}^{+}\right)$of molecules and deuterons $\left(\mathrm{D}^{+}\right)$from deuterated solvent in solution as well as in GP process (i.e., H/D exchange with residual light water into ion trap as back HDX). To obtain a homogeneous annotation when it concerns hydride/deuteride (i.e., $\mathrm{H}^{-} / \mathrm{D}^{-}$) exchanges, this acronym was modified into $\langle H D X>$. Unresolved hydrogen/deuterium exchanges will be termed as $\mathrm{H} / \mathrm{D}$ exchanges. 


\section{Results and discussion}

Negative ESI mass spectrum of the F6P/R mixture solubilized in pure $\mathrm{H}_{2} \mathrm{O}$ displayed the $[\mathrm{F} 6 \mathrm{P}-\mathrm{H}]^{-}$and $[R-H]^{-}$anions at $\mathrm{m} / \mathrm{z} 259$ and m/z 173, respectively. In addition, the NCC-representative anions $[(\mathrm{F} 6 \mathrm{P}+\mathrm{R})-\mathrm{H}]^{-}$and $[(\mathrm{F} 6 \mathrm{P}+\mathrm{R}-\mathrm{H}+\mathrm{Na})-\mathrm{H}]^{-}$appear at $\mathrm{m} / \mathrm{z} 433$ and $\mathrm{m} / \mathrm{z} 455$, respectively (Figure S2a). The ESI mass spectrum of the same mixture dissolved in $\mathrm{D}_{2} \mathrm{O}$ (Figure $\mathbf{S 2} \mathbf{b}$ ) is characterized by the presence of deuterated anionic species in which mobile protons are almost completely exchanged (at carboxyl, hydroxyl, guanidino and amino groups). Roughly 98-99 \% of D-labeling was reached for each monomer species i.e. labeled [F6 $\left.\mathrm{P}_{\mathrm{d} 6}-\mathrm{D}\right]^{-}$and $\left[\mathrm{R}_{\mathrm{d} 7^{-}}-\mathrm{D}\right]^{-}$at $\mathrm{m} / \mathrm{z} 264$ and $\mathrm{m} / \mathrm{z} 179$, respectively. Also, the deprotonated $\left[\left(\mathrm{F}_{6} \mathrm{P}_{\mathrm{d} 6}+\mathrm{R}_{\mathrm{d} 7}\right)-\mathrm{D}\right]^{-}$dimers $(\mathrm{m} / \mathrm{z} 445)$ and the sodiated $\left[\left(\mathrm{F} 6 \mathrm{P}_{\mathrm{d} 6}+\mathrm{R}_{\mathrm{d} 7}-\mathrm{D}+\mathrm{Na}\right)-\mathrm{D}\right]^{-}$complex anions ( $\mathrm{m} / \mathrm{z} 466$ ) are quantitatively produced (see Table $\mathbf{S 1}$ in Supporting Information). Such almost quantitative HDX indicates that gas phase back HDX (i.e., proton exchange with the residual light water) into the ion storage device (during ion injection and analytical scan) are negligible under our experimental conditions.

1. Gas phase dissociations of sodiated $\mathrm{F} \mathrm{P}_{\mathrm{d} 6} / \mathbf{R}_{\mathrm{d} 7}$ non-covalent complex anions showed unexpected inter-partner H/D exchanges

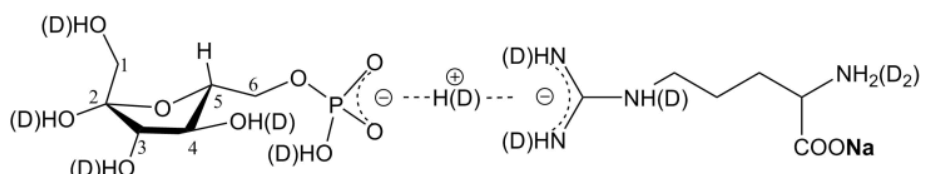

(a) $(\mathrm{HB})$

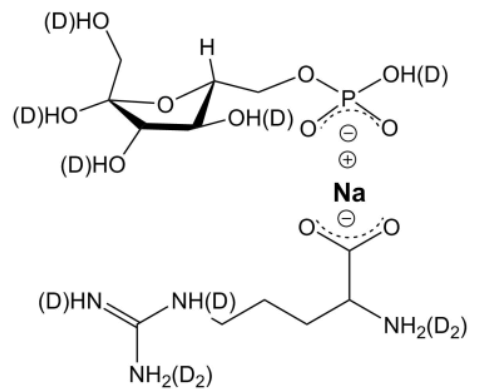

(b) $\left(\mathrm{SSA}_{\text {can }}\right)$

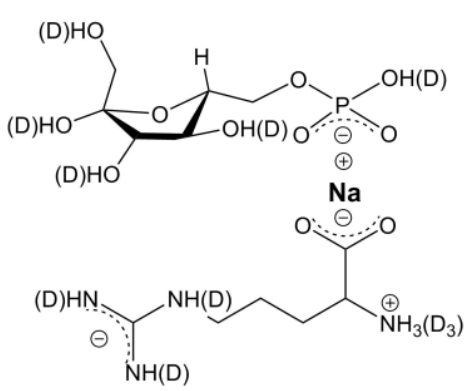

(c) $\left(\mathrm{SSA}_{\mathrm{zw}}\right)$

Scheme 1. Possible structures of the sodiated [(F6P+R-H+Na)-H] ${ }^{-} \mathrm{NCC}$ anion forms (and in bracket as labeled [( $\left.\left.\mathrm{FGP}_{\mathrm{d} 6}+\mathrm{R}_{\mathrm{d} 7}-\mathrm{D}+\mathrm{Na}\right)-\mathrm{D}\right]^{-}$species): (a) hydrogen bonded (HB) form; deprotonated solvated salt (SSA) forms with (b) canonical (SSA $\left.{ }_{c a n}\right)$ and (c) zwitterion $\left(\mathrm{SSA}_{\mathrm{zw}}\right)$ arginine structures.

Under CID conditions, the sodiated [(F6P+R-H+Na)-H] anion $(\mathrm{m} / \mathrm{z} 455)$ mainly dissociates with the sodiated arginine salt release, giving an $[\mathrm{F} 6 \mathrm{P}-\mathrm{H}]^{-}$anion $(\mathrm{m} / \mathrm{z} 259)$ (Figure S3a in Supporting Information). ${ }^{41}$ Such a monomer ion can be formed by direct splitting of partners from both 
hydrogen bonded (HB) and deprotonated solvated salt (SSA) forms of the sodiated NCC anions (Scheme 1). A minor competitive $\mathrm{C}_{3} \mathrm{H}_{6} \mathrm{O}_{3}$ loss from the fructose moiety from the sodiated NCC anion yielded the ion at $\mathrm{m} / \mathrm{z} 365$, through the cross-ring cleavage such as it occurs from the free $[\mathrm{F} 6 \mathrm{P}-\mathrm{H}]^{-}$ anions, ${ }^{71,72}$ while preserving the non-covalent binding. This suggests the existence of strong ionic interactions within the sodiated F6P/R complex ions. Such interactions could be attributed to salt or solvated salt forms of the sodiated $[(\mathrm{F} 6 \mathrm{P}+\mathrm{R}-\mathrm{H}+\mathrm{Na})-\mathrm{H}]^{-}$anions (Scheme 1), similarly to what has been demonstrated by quantum calculations in a previous work. ${ }^{41}$ As proposed in the fragmentation mechanisms of monosaccharide anions,$^{73}$ the free negative charge of $\mathrm{SSA}_{\mathrm{zW}}$ that forms here induces cross-ring cleavages. When taking into account such mechanisms, only $\mathrm{SSA}_{z w}$ forms involve a free negative charge (as possible ZW partner for the sodiated arginine salt) independently of noncovalent ionic interactions (Scheme 1). ${ }^{31,74}$ In the HCD spectrum (Figure S3b) the loss of $\left(\mathrm{R}^{2} \mathrm{C}_{3} \mathrm{H}_{6} \mathrm{O}_{3}\right)$ was detected, instead of the $\mathrm{C}_{3} \mathrm{H}_{6} \mathrm{O}_{3}$ loss observed under $\mathrm{CID}$ conditions.

Significant differences were observed when comparing product ion spectra of labeled sodiated $\left[\left(\mathrm{F} \mathrm{P}_{\mathrm{d} 6}+\mathrm{R}_{\mathrm{d} 7}-\mathrm{D}+\mathrm{Na}\right)-\mathrm{D}\right]^{-}$anion (m/z 466, as sodiated NCC-d11) obtained under CID or HCD conditions (Figure 1).
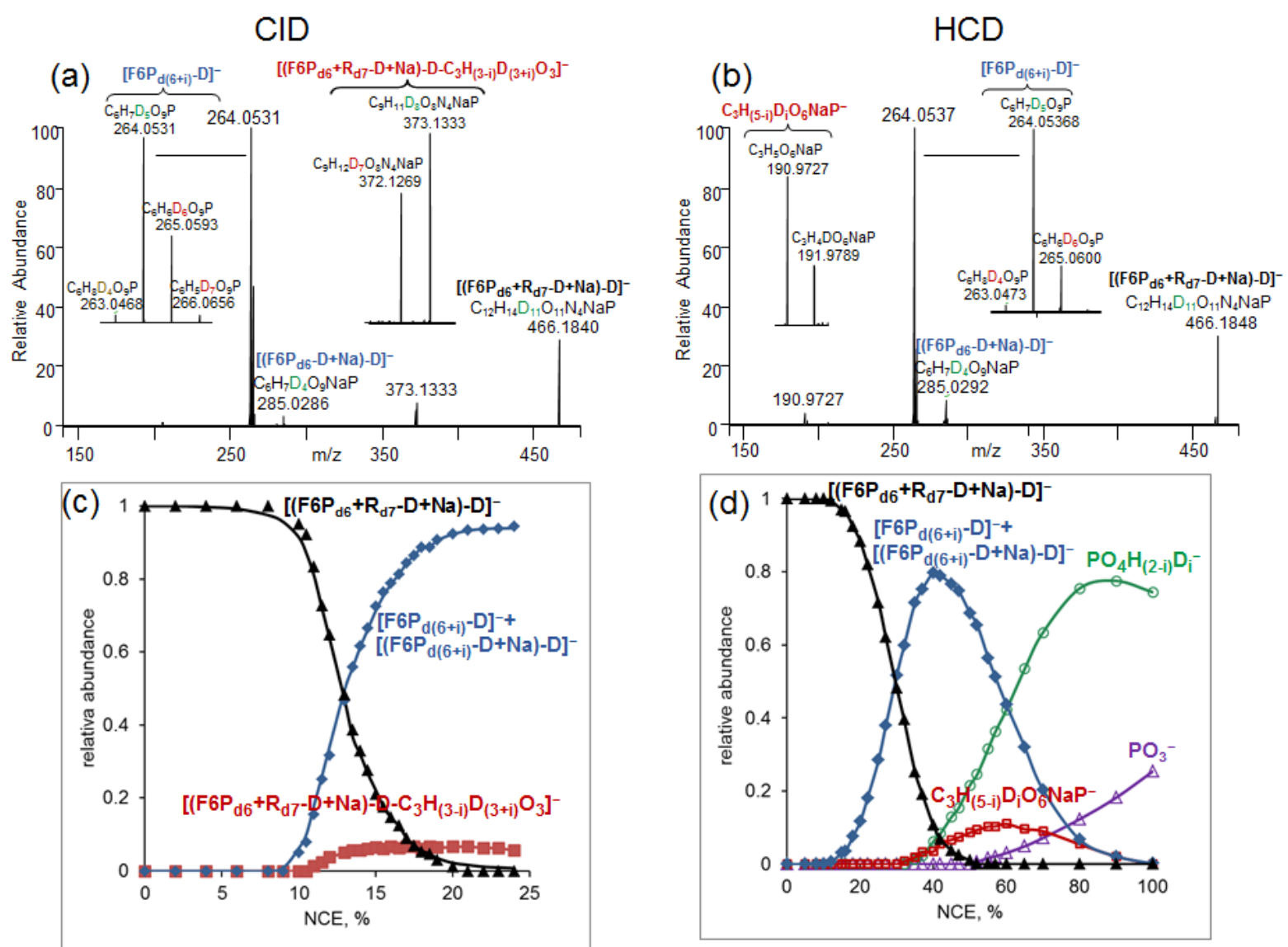

Figure 1. Product ion spectra of labeled $\left[\left(\mathrm{F}_{6 \mathrm{~d}} \mathrm{P}_{\mathrm{d}}+\mathrm{R}_{\mathrm{d} 7}-\mathrm{D}+\mathrm{Na}\right)-\mathrm{D}\right]^{-}$anion $(\mathrm{m} / \mathrm{z} 466)$ recorded under (a) $\mathrm{CID}$ (ActQ $=0.25, \mathrm{NCE}=15 \%$ and $\mathrm{Act} \mathrm{T}=10 \mathrm{~ms}$ ) (fragment ions with abundances lower than $1 \%$ were not reported) and (b) $\mathrm{HCD}(\mathrm{NCE}=40 \%, \mathrm{ActT}=0.1 \mathrm{~ms}$ ) modes with zooms onto isotopologues of labeled 
$\left[\mathrm{F} 6 \mathrm{P}_{\mathrm{d} 6}-\mathrm{D}\right]^{-}$(at $\left.\mathrm{m} / \mathrm{z} 264\right)$ and $\left[\left(\mathrm{F} 6 \mathrm{P}_{\mathrm{d} 6}+\mathrm{R}_{\mathrm{d} 7}-\mathrm{D}+\mathrm{Na}\right)-\mathrm{D}-\mathrm{C}_{3} \mathrm{H}_{3} \mathrm{D}_{3} \mathrm{O}_{3}\right]^{-}(\mathrm{m} / \mathrm{z} 373)$ product ions. ERMS breakdown curves of the labeled [(F6P $\left.\left.\mathrm{P}_{\mathrm{d} 6}+\mathrm{R}_{\mathrm{d} 7}-\mathrm{D}+\mathrm{Na}\right)-\mathrm{D}\right]^{-}$anion $(\mathrm{m} / \mathrm{z} 466)$ activated by (c) CID (ActT=10 ms, ActQ $=0.25$ ) and (d) HCD (ActT=0.1 ms) modes. Curves were obtained by plotting the integrated isotopologue ion abundances normalized to the total ionic current for the following ions marked as solid triangle for $\left[\left(\mathrm{F} 6 \mathrm{P}_{\mathrm{d} 6}+\mathrm{R}_{\mathrm{d} 7}-\mathrm{D}+\mathrm{Na}\right)-\mathrm{D}\right]^{-}$precursor ions $(\mathrm{m} / \mathrm{z} 466)$, solid rhombus for the sum of abundances of $\left[\mathrm{F} 6 \mathrm{P}_{\mathrm{d}(6+\mathrm{i})}-\mathrm{D}\right]^{-}$and $\left[\left(\mathrm{F} \mathrm{P}_{\mathrm{d}(6+\mathrm{i})}-\mathrm{D}+\mathrm{Na}\right)-\mathrm{D}\right]^{-}(\mathrm{i}=0,1$ and 2$)$ monomer anions, solid square for $\left[\left(\mathrm{FGP}_{\mathrm{d} 6}+\mathrm{R}_{\mathrm{d} 7}-\mathrm{D}+\mathrm{Na}\right)-\mathrm{D}-\mathrm{C}_{3} \mathrm{H}_{(3-\mathrm{i})} \mathrm{D}_{(3+\mathrm{i})} \mathrm{O}_{3}\right]^{-}\left(\mathrm{i}=\mathrm{O}, 1\right.$ and 2), square for $\mathrm{C}_{3} \mathrm{H}_{(5-\mathrm{i})} \mathrm{D}_{\mathrm{i}} \mathrm{O}_{6} \mathrm{NaP}^{-}$( $\mathrm{i}=0$ and 1$)$, triangle for $\mathrm{PO}_{3}^{-}$and circle for $\mathrm{PO}_{4} \mathrm{H}_{(2-i)} \mathrm{D}_{\mathrm{i}}^{-}(\mathrm{i}=0,1$ and 2$)$ anions.

(a) The CID spectrum of the sodiated D-labeled NCC-d11 anion (slow heating conditions, S2 in Supporting Information, ${ }^{75,76}$ Figure 1a) displays the same product ions as the unlabeled sodiated NCC species (Figure S2a) with the expected D-retention i.e., a major [F6P $\left.\mathrm{d}_{\mathrm{d}}-\mathrm{D}\right]^{-}$monomer ions $(\mathrm{m} / \mathrm{z} 264$, $100 \%$ of relative abundance) and weakly abundant $\left[\left(\mathrm{F} 6 \mathrm{P}_{\mathrm{d} 6}+\mathrm{R}_{\mathrm{d} 7}-\mathrm{D}+\mathrm{Na}\right)-\mathrm{D}-\mathrm{C}_{3} \mathrm{H}_{3} \mathrm{D}_{3} \mathrm{O}_{3}\right]^{-}(\mathrm{m} / \mathrm{z} 373,6 \%)$ anions were mainly detected. Surprisingly, these product ions were accompanied by unexpected labeled species at m/z 265 and m/z 372 and, in addition, by much weaker m/z 266 and m/z 371 .

Rather unexpectedly, we observed a sort of intensity balance between D-enriched and D-depleted product ions. Indeed, what is relatively gained by one significant species (i.e., [F6P $\left.\mathrm{F}_{\mathrm{d}-\mathrm{D}}\right]^{-}$at $\mathrm{m} / \mathrm{z} 265$ instead of the expected $\left[\mathrm{FGP}_{\mathrm{d} 6}-\mathrm{D}\right]^{-}$at $\left.\mathrm{m} / \mathrm{z} 264\right)$ seems almost lost by the other (i.e., $\left[\left(\mathrm{FGP}_{\mathrm{d} 6}+\mathrm{R}_{\mathrm{d} 7^{-}}\right.\right.$ $\left.\mathrm{D}+\mathrm{Na})-\mathrm{D}-\mathrm{C}_{3} \mathrm{H}_{2} \mathrm{D}_{4} \mathrm{O}_{3}\right]^{-}$at $\mathrm{m} / \mathrm{z} 372$ instead of $\left.\left[\left(\mathrm{F}_{6} \mathrm{P}_{\mathrm{d} 6}+\mathrm{R}_{\mathrm{d} 7}-\mathrm{D}+\mathrm{Na}\right)-\mathrm{C}_{3} \mathrm{H}_{3} \mathrm{D}_{3} \mathrm{O}_{3}\right]^{-}, \mathrm{m} / \mathrm{z} \quad 373\right)$. The corresponding losses $\left.\mathrm{C}_{3} \mathrm{H}_{(3-\mathrm{i})} \mathrm{D}_{(3+i)} \mathrm{O}_{3}\right]^{-}\left(\mathrm{i}=0,1\right.$ and 2 ) were termed $\mathrm{C}_{(3)}$ neutral cluster losses. Note that such a fragmentation behavior is not observed from deprotonated dimer [F6 $\left.\mathrm{P}_{\mathrm{d} 6}+R_{\mathrm{d} 7}-\mathrm{D}\right]^{-}(\mathrm{m} / \mathrm{z} 445)$ (Figure S4). The major HB form of this deprotonated NCC-d12 dissociates exclusively by partner splitting (i.e., non-covalent bonding cleavage) yielding expected labeled [F6P $\left.\mathrm{d}_{\mathrm{d}}-\mathrm{D}\right]^{-}$ions $(\mathrm{m} / \mathrm{z} 264)$. In contrast, the sodiated NCC-d11 anion undergoes competitive fragmentation pathways i.e., direct partner splitting and cross-ring cleavages while preserving non-covalent binding. The formation of the unexpected labeled product ions suggests NCC isomerization with potential inter-partner H/D exchanges (see below).

ERMS breakdown curves of the sodiated NCC-d11 anion under CID conditions (Figure 1c) show a slow increase of product ion cluster abundances with the collision energy, similar to that of the unlabeled species (Figure S3c). As soon as the parent ion disappears (beyond NCE of 20\%), the abundance of each product ion cluster becomes constant, meaning that no (or weak) consecutive fragmentation pathways occur as expected in CID mode (S2 in Supporting Information). Importantly, the phosphate and metaphosphate ions were not detected even at a lower LMCO value (e.g. lowest $\mathrm{m} / \mathrm{z} 70$ for ActQ 0.15).

b) Product ion spectrum recorded under HCD conditions displays some differences (Figure 1b) compared to that of CID (Figure 1a). The relative contribution of $\left[\mathrm{F} 6 \mathrm{P}_{\mathrm{d} 7}-\mathrm{D}\right]^{-}$product ion at $\mathrm{m} / \mathrm{z} 265$ is reduced in abundance from $30 \%$ (Figure 1a) to $15 \%$ (Figure $1 \mathrm{~b}$ ) of the base peak at $\mathrm{m} / \mathrm{z} 264$. In 
addition, instead of the non-covalent product ions i.e., $\mathrm{m} / \mathrm{z} 372 / 373$ ion cluster detected in the CID experiments (Figure 1a), the $\mathrm{m} / \mathrm{z} 191 / 192$ doublet corresponding to $\left[\left(\mathrm{F}_{6} \mathrm{P}_{\mathrm{d} 6}+\mathrm{R}_{\mathrm{d} 7}-\mathrm{D}+\mathrm{Na}\right)-\mathrm{D}-\left(\mathrm{R}_{\mathrm{d} 7}+\mathrm{C}_{3} \mathrm{H}_{3}\right.\right.$ $\left.\left.{ }_{i} \mathrm{D}_{3+\mathrm{i}} \mathrm{O}_{3}\right)\right]^{-}$(i.e., $\mathrm{C}_{3} \mathrm{H}_{(5-i)} \mathrm{D}_{i} \mathrm{O}_{6} \mathrm{NaP}^{-}$) product ions (with $\mathrm{i}=0$ and 1, Figure $1 \mathrm{~b}$ ) appeared at higher NCE. In the low $\mathrm{m} / \mathrm{z}$ range, the labeled phosphate $\mathrm{PO}_{4} \mathrm{H}_{(2-i)} \mathrm{D}_{\mathrm{i}}^{-}(\mathrm{i}=0,1$ and 2 ) isotopologue ion cluster at $\mathrm{m} / \mathrm{z} 99$, $\mathrm{m} / \mathrm{z} 98$ and $\mathrm{m} / \mathrm{z} 97$ and the metaphosphate $\mathrm{PO}_{3}{ }^{-}$anion at $\mathrm{m} / \mathrm{z} 79$ were observed under $\mathrm{HCD}$ conditions because of the absence of LMCO. ${ }^{56}$ Therefore, their formation (not observed under CID conditions) is likely due to consecutive dissociations using such activation conditions (see S2 in Supporting Information).

Moreover, the D-enrichment observed for the $\left[\mathrm{F}_{\mathrm{f}} \mathrm{P}_{\mathrm{d} 6^{-}}-\mathrm{D}\right]^{-}$product anion $(\mathrm{m} / \mathrm{z} 264)$ is only represented by the $\mathrm{m} / \mathrm{z} 265$ anion (Figure $\mathbf{1 b}$ ) and is not accompanied by a detectable product ion with $\mathrm{D}$ depletion as a counterpart in the CID spectrum (Figure 1a). A lower level of D-enrichment can be explained by the predominant $\mathrm{m} / \mathrm{z} 264$ formation through partner splitting rather than rearrangement under HCD conditions.

ERMS breakdown curves of [(F6P $\left.\left.\mathrm{d}_{\mathrm{d}}+\mathrm{R}_{\mathrm{d} 7}-\mathrm{D}+\mathrm{Na}\right)-\mathrm{D}\right]^{-}$(Figure 1d) in $\mathrm{HCD}$, are almost identical to those of unlabeled sodiated [(F6P+R-H+Na)-H] $]^{-}$anion (Figure S3d). The $\mathrm{m} / \mathrm{z} 264 / 265$ doublet $\left(\left[\mathrm{F} 6 \mathrm{P}_{\mathrm{d} 6}-\mathrm{D}\right]^{-}\right.$and $\left.\left[\mathrm{FGP}_{\mathrm{d} 7^{-}} \mathrm{D}\right]^{-}\right)$appears early and at a higher energy, the $\mathrm{m} / \mathrm{z} 191 / 192$ doublet $\left(\mathrm{C}_{3} \mathrm{H}_{(5-i)} \mathrm{D}_{i} \mathrm{O}_{6} \mathrm{NaP}^{-}\right.$with $\mathrm{i}=0$ and 1) is produced very likely from the consecutive $\left[\left(\mathrm{F} 6 \mathrm{P}_{\mathrm{d} 7}-\mathrm{D}+\mathrm{Na}\right)-\mathrm{D}\right]^{-}$dissociations through cross-ring cleavages. At high NCE values, the isotopologue $\mathrm{PO}_{4} \mathrm{H}_{(2-i)} \mathrm{D}_{i}^{-}(\mathrm{i}=0,1$ and 2$)$ anions $(\mathrm{m} / \mathrm{z}$ 99/98/97) and the $\mathrm{PO}_{3}{ }^{-}$anion $(\mathrm{m} / \mathrm{z}$ 79) grow up. Inorganic phosphorous anions are likely generated from the consecutive dissociations of the $\mathrm{m} / \mathrm{z} 264 / 265$ and $\mathrm{m} / \mathrm{z}$ 191/192 clusters possible in HCD mode (S2 in Supporting Information).

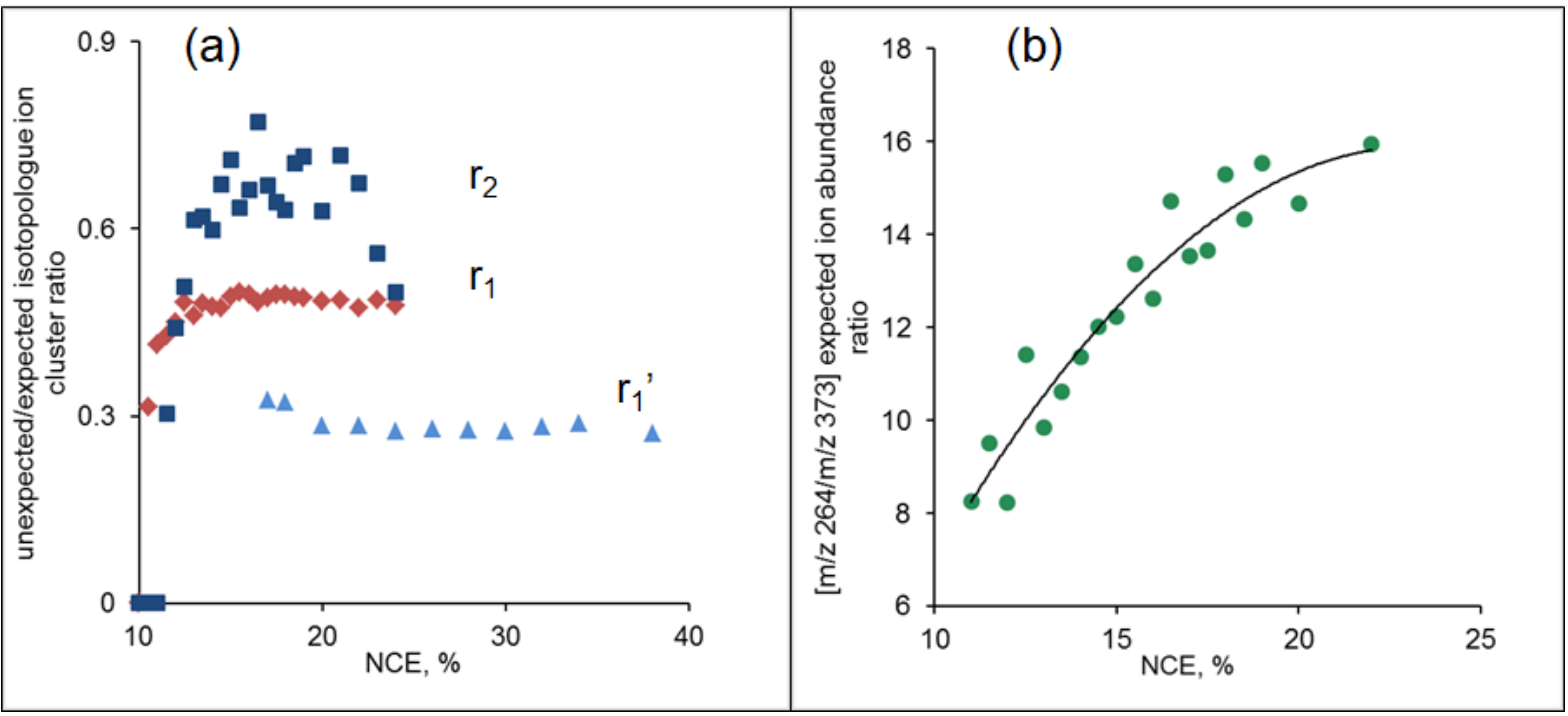

Figure 2. (a) Evolution of the ratios of the unexpected labeled ion abundances sum over the expected ion abundance $r_{1}, r_{2}$ and $r_{1}{ }^{\prime}$ as a function of NCE values: $r_{1}=\left(I_{265}+I_{266}\right) / I_{264}$, and $r_{2}=\left(I_{371}+l_{372}\right) / I_{373}$ were 
determined under CID conditions and $\mathrm{r}_{1}^{\prime}=\mathrm{I}_{265} / \mathrm{I}_{264}$ obtained under HCD conditions; (b) evolution of the ratio of the peak intensities $\mathrm{I}_{264} / \mathrm{I}_{373}$ as a function of NCE under CID conditions.

To get deeper insight into the impact of the collisional energy on the $D$ enrichment/D-depletion, the evolution of the $\Sigma l_{\text {unexpected }} / l_{\text {expected }}$ ratio was explored. The $r_{1}$ ratio corresponds to the D-enrichment revealed by the F6P monomer anions, while $r_{2}$ is related to the D-depletion expressed by the product ions from sugar cross-ring cleavages under CID conditions.

The $r_{1}^{\prime}<r_{1}$ values reflect the enhanced direct $m / z 264$ formation through partner splitting under HCD conditions. Moreover, the constant D-enrichment degree of the F6P partner over all NCE range in $\mathrm{HCD}$ experiments is likely due to shorter excitation time and higher transfer energy, disfavoring unexpected $\mathrm{H} / \mathrm{D}$ migration (isomerization processes) in contrast to CID (Figure 2a).

The $r_{1}$ and $r_{2}$ values slightly increase up to NCE $=17-18 \%$ and then remain roughly constant. Larger scatter of the $r_{2}$ values relatively to the $r 1$ ones essentially originate from experimental variability in the measurements of the weakly abundant product ions at $\mathrm{m} / \mathrm{z} 373 / 372 / 371$ »The constant $r_{1}$ ratio (and also $r_{2}$, within the experimental errors) indicates that under higher excitation conditions, the main part of the precursor ion population (more than $90 \%$, Figure 1c) is dissociated and/or directly ejected from the ion trap, while the contribution of inter partner $\mathrm{H} / \mathrm{D}$ exchanges for the survivor part does not seem to change anymore.

Furthermore, the observed difference between $r_{1}$ and $r_{2}$ values (Figure 2a) might be attributed to several causes. First, the higher $r_{2}$ value can be explained by back HDX with residual light water during prolonged storage in the ion trap mass analyzer (see $\mathbf{S 2}$ in Supporting Information). ${ }^{77-81}$ Alternatively, the lower $r_{1}$ ratio could be explained by the co-existence of several $\mathrm{m} / \mathrm{z} 264$ species with different origins (Scheme 2). First m/z 264 could be produced through direct partner splitting from the sodiated NCC-d11 anions within HB and SSA structures (pathway (a) in Scheme 2). In addition, possible isomerization of sodiated NCC-d11 within $\mathrm{SSA}_{z w}$ involving cross-ring cleavages yields an acyclic intermediate from which partner splitting can also occur resulting in $\mathrm{m} / \mathrm{z} 264$ (pathway (b) in Scheme 2). Further sodiated NCC-d11 isomerization, certainly involves inter-partner $\mathrm{H} / \mathrm{D}$ exchanges, giving rise either to the unexpected $\mathrm{m} / \mathrm{z} 265$ and $\mathrm{m} / \mathrm{z} 266$ product ions by partner splitting or to the formation of $\mathrm{m} / \mathrm{z} 372$ and m/z 371 (pathway (c) in Scheme 2).

Fig. 2 b presents the evolution of $\mathrm{I}_{264} / \mathrm{I}_{373}$ ratio as a function of excitation energy to highlight the relationship between competitive dissociation pathways. Indeed, the increase in this ratio is consistent with the enhanced partner splitting by non-covalent bond (NCB) cleavage at higher energy (m/z 264 production) relatively to CB cleavage ( $\mathrm{m} / \mathrm{z} 373$ generation), mainly observed at lower energy). ${ }^{82}$ 


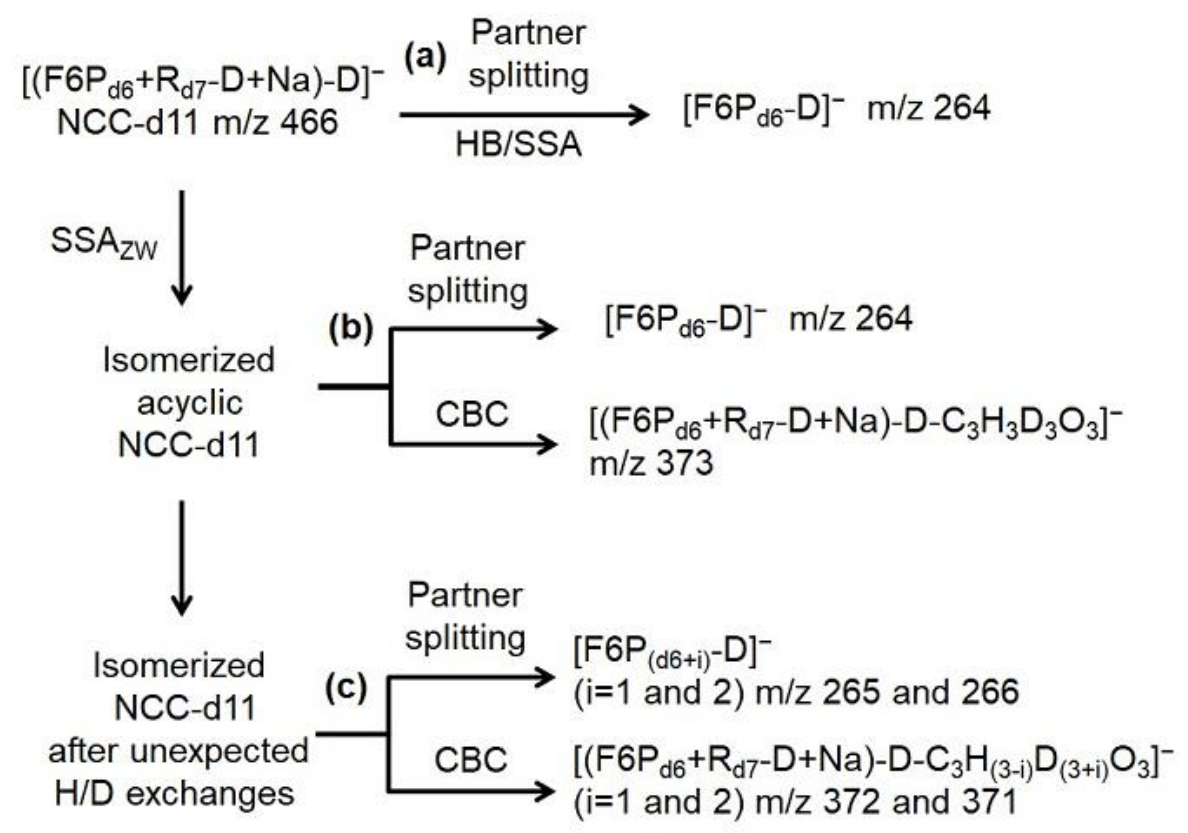

Scheme 2. Possible dissociation pathways of the sodiated NCC-d11 anions ( $\mathrm{m} / \mathrm{z} 466)$ through splitting of partners and cross-ring covalent cleavage pathways (the other dissociation pathways related to cross-ring fructose cleavages and resulting in other ion clusters are not reported).

\section{Exploring the impact of ActT on the covalent bond cleavages, D-enrichment versus D-depletion} and selective back HDX

In order to confirm the apparent inter-partner H/D exchanges using CID, the dissociation behavior of the sodiated NCC-d11 anion in CID mode was explored using a wide range of excitation durations i.e., ActT from $100 \mathrm{~ms}$ to $3000 \mathrm{~ms}$ and under a weak excitation voltage (NCE=8\%). Under these conditions, the internal energy of the stored precursor ions, submitted to weak resonant excitation and prolonged activation time, increases very slowly ("slower" heating conditions), thereby favoring isomerization/rearrangement processes). ${ }^{82}$

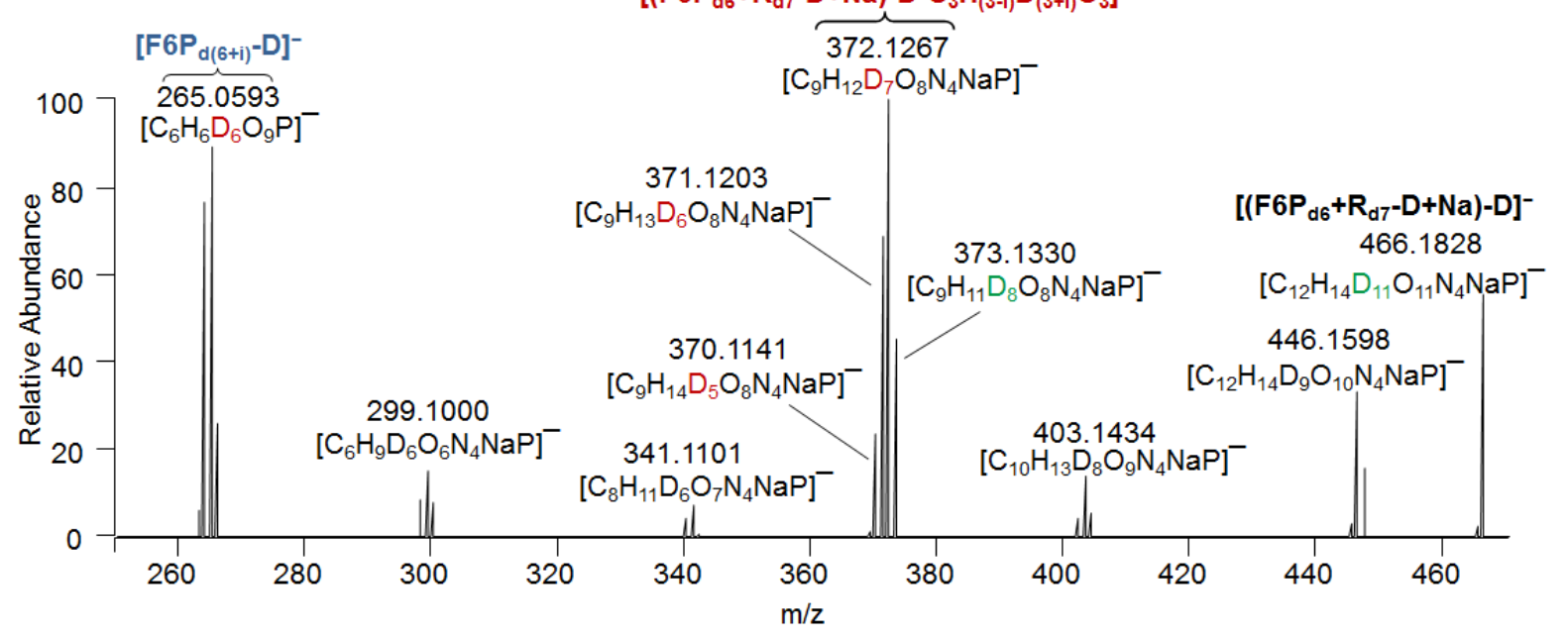


Figure 3. $\mathrm{CID}$ spectrum of the labeled $\left[\left(\mathrm{F} 6 \mathrm{P}_{\mathrm{d} 6}+\mathrm{R}_{\mathrm{d} 7}-\mathrm{D}+\mathrm{Na}\right)-\mathrm{D}\right]^{-}$anions $(\mathrm{m} / \mathrm{z} 466)$ recorded at $\mathrm{Act} T=3000$ $\mathrm{ms}, \mathrm{NCE}=8 \%$ and $\mathrm{ActQ}=0.15$. Note that excitation parameters were changed compared to Figure 1 , to reach "slower" heating conditions, i.e., NCE was reduced to maintain a non-negligible part of the $\left[\left(\mathrm{F}_{6} \mathrm{P}_{\mathrm{d} 6}+\mathrm{R}_{\mathrm{d} 7}-\mathrm{D}+\mathrm{Na}\right)-\mathrm{D}\right]^{-}$precursor ions in the ion trap up to $3000 \mathrm{~ms}$.

\section{(a) Enhancement of covalent bond cleavages and inter-partner H/D exchanges with the increase in} ActT

Under default ActT conditions ( $A c t Q=0.25$ and $A c t T=10 \mathrm{~ms}$, in Figure 1a), product ions related to $C B$ cleavages were mainly represented by weakly abundant isotopologue $\mathrm{m} / \mathrm{z} 373 / 372 / 371$ ion cluster. In contrast, at a long activation time (see Figure 3 ), the abundances of these product ions are significantly increased. Indeed, $\mathrm{m} / \mathrm{z} 372$ becomes the base peak, reflecting the reinforcement of the CB cleavage pathways compared to the NCB cleavages (partner splitting). The relative abundance of $\mathrm{m} / \mathrm{z} 264$ ions decreases to $77 \%$ of the base peak (it was the base peak in Figure 1a), while that of the $\mathrm{m} / \mathrm{z} 373$ ion increases from $5 \%$ to $48 \%$ of the base peak (Figure 3). Abundant $\mathrm{m} / \mathrm{z} 447 / 446$ ion cluster related to $\mathrm{DHO} / \mathrm{D}_{2} \mathrm{O}$ losses is observed. Furthermore, other cross-ring cleavages take place, resulting in additional minor isotopologue product ion clusters at $\mathrm{m} / \mathrm{z}$ 404/403/402, $\mathrm{m} / \mathrm{z}$ 342/341/340, and $\mathrm{m} / \mathrm{z} 300 / 299 / 298$. They were generated by the formal losses of, $\mathrm{C}_{2} \mathrm{H}_{2} \mathrm{D}_{2} \mathrm{O}_{2} / \mathrm{C}_{2} \mathrm{H}_{1} \mathrm{D}_{3} \mathrm{O}_{2} / \mathrm{C}_{2} \mathrm{D}_{4} \mathrm{O}_{2}$ (i.e., $\mathrm{C}_{(2)}$ neutral cluster), $\mathrm{C}_{4} \mathrm{H}_{4} \mathrm{D}_{4} \mathrm{O}_{4} / \mathrm{C}_{4} \mathrm{H}_{3} \mathrm{D}_{5} \mathrm{O}_{4} / \mathrm{C}_{4} \mathrm{H}_{2} \mathrm{D}_{6} \mathrm{O}_{4}$ (i.e., $\mathrm{C}_{(4)}$ neutral cluster) and $\mathrm{C}_{6} \mathrm{H}_{6} \mathrm{D}_{4} \mathrm{O}_{5} / \mathrm{C}_{6} \mathrm{H}_{5} \mathrm{D}_{5} \mathrm{O}_{5} / \mathrm{C}_{6} \mathrm{H}_{4} \mathrm{D}_{6} \mathrm{O}_{5}$ (i.e., $\mathrm{C}_{(6)}$ neutral cluster). Such losses are comparable to those of the fructose-6-phosphate anion observed in an ion trap mass analyzer. ${ }^{71,72}$ They are likely due to stepwise sodiated NCC-d11 isomerization processes involving H/D exchanges and cross-ring cleavages which compete with the loss of sodiated arginine salt yielding the $\mathrm{m} / \mathrm{z}$ 264/265/266 product ion cluster. The product ion clusters related to the $\mathrm{C}_{(2)}, \mathrm{C}_{(4)}$, and $\mathrm{C}_{(6)}$ neutral loss clusters were not sufficiently abundant and, thus not further explored.

Figure 3 shows that higher ActT values tend to favor D-depletion/D-enrichment. A large isotopologue ion cluster at $\mathrm{m} / \mathrm{z} \quad 373 / 372 / 371 / 370 \quad\left(C_{(3)}\right.$ neutral cluster related to formal $\mathrm{C}_{3} \mathrm{H}_{3} \mathrm{D}_{3} \mathrm{O}_{3} / \mathrm{C}_{3} \mathrm{H}_{2} \mathrm{D}_{4} \mathrm{O}_{3} / \mathrm{C}_{3} \mathrm{HD}_{5} \mathrm{O}_{3} / \mathrm{C}_{3} \mathrm{D}_{6} \mathrm{O}_{3}$ losses) is detected with abundance is comparable to that of the m/z 266/265/264 cluster(with m/z 263 was neglected, see below). Nevertheless, even at AcT=3000 $\mathrm{ms}$, the $\mathrm{m} / \mathrm{z}(264+\mathrm{i})$ product ions are obtained by mainly one unexpected $\mathrm{H} / \mathrm{D}$ exchange and to a lesser extent, by a second one. The fact that a maximum of two H/D exchanges are detected for Denrichment although other mobile deuterons are available, indicates that these exchanges are highly specific. In contrast, product ions generated by $C_{(3)}$ neutral cluster loss involve an additional isotopologue ion at $\mathrm{m} / \mathrm{z} 370$, which likely originates only from back HDX (see discussion below). 


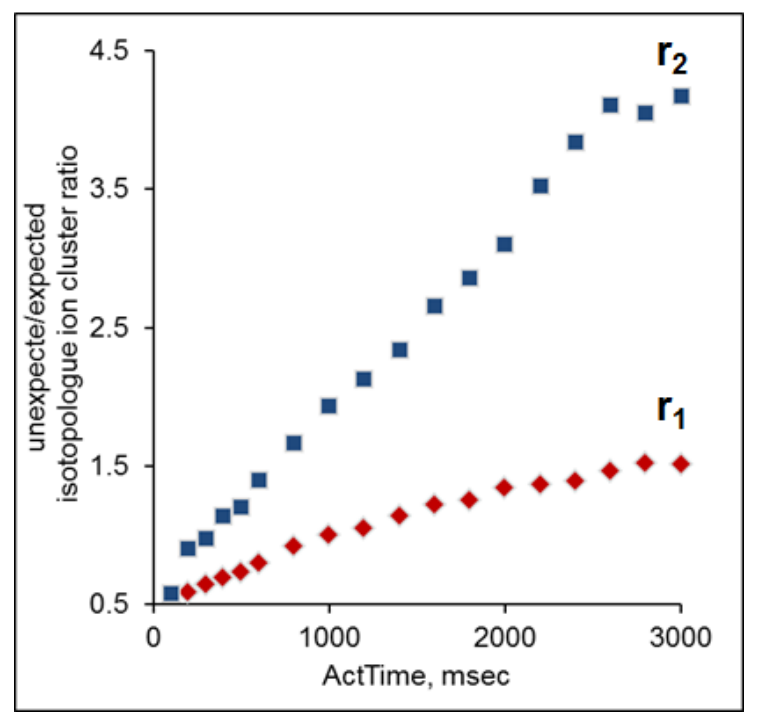

Figure 4. Evolution of formal D-enrichment ( $r_{1}$ ratio) and D-depletion $\left(r_{2}\right.$ ratio) as a function of ActT using $\mathrm{CID}$ mode (fixed parameters: $\mathrm{ActQ}=0.15, \mathrm{NCE}=8 \%$ ).

Figure 4 shows the evolution of the $r_{1}$ and $r_{2}$ ratios as a function of ActT. According to the obtained curves, the $r_{2}$ values are greater than those of $r_{1}$ regardless the ActT value. The D-depletion and Denrichment are characterized by maximum values of $r_{2}=4.1$ and $r_{1}=1.4$ (Figure 4) compared to the maximum values of 0.7 and 0.5 respectively, obtained previously at fixed ActT=10 ms (Figure 2a). The increases in the $r_{2}$ and $r_{1}$ ratios with the ActT growth is consistent with the favored isomerization/rearrangement processes (resulting in the enhanced CB cleavages and inter-partner $H / D$ exchanges) driven by both the low internal energy transfer and the long ion storage/excitation time (kinetic shift effect). ${ }^{82}$ Moreover, the more pronounced slope of $r_{2}$ plot compared to that of $r_{1}$ reflects an enhanced back HDX of the relaxed ( $\mathrm{m} / \mathrm{z}$ 373-i) product ions ( $\mathrm{i}=0,1$ and 2 ) under "slower" heating conditions, favoring ion/molecule processes.

\section{(b) Importance of ion relaxation for back HDX}

A priori, the gas phase back HDX, reinforcing D-depletion effect, only takes place from the isotopologue $\mathrm{m} / \mathrm{z} 373 / 372 / 371$ product ion cluster and, to a lesser extent, from the non-covalent product ions related to the losses of the $C_{(2)}, C_{(4)}$ and $C_{(6)}$ clusters (Figure 3). Back HDX from the $\mathrm{m} / \mathrm{z}$ 466 yielding $\mathrm{m} / \mathrm{z} 465$ was not observed. Very weak relative abundance of the $\left[\mathrm{F} 6 \mathrm{P}_{\mathrm{d} 5}-\mathrm{D}\right]^{-}$anion at $\mathrm{m} / \mathrm{z}$ $263(3 \%)$ compared to that of the $\left[\mathrm{F}_{6} \mathrm{P}_{\mathrm{d} 6}-\mathrm{D}\right]^{-}$anion at $\mathrm{m} / \mathrm{z} 264(75 \%)$ suggests that for this product ion back HDX are also strongly unfavored.

Based on the hypothesis of gas phase back HDX, ${ }^{77-81}$ one can assume a formation of HB between one (or two) water molecule(s) and a charged site of the product ions i.e., $\mathrm{m} / \mathrm{z} 373 / 372 / 371$, presumably, an alkoxide site. The lifetime of the resulting solvated form must be long enough to undergo 
ion/molecule reactions. Importantly, the acidity (i.e., $\Delta \mathrm{H}^{\circ}{ }_{\text {acid }}$ ) of the anion reactive site must be relatively close to that of a neutral, e.g. $\mathrm{H}_{2} \mathrm{O}$ (or $2 \mathrm{H}_{2} \mathrm{O}$, see below), unless assisted by a second acidic site that can reduce the critical energy of the proton (or deuteron) exchange. ${ }^{83}$ Therefore, HDX can be achieved from the $\mathrm{m} / \mathrm{z} 373 / 372 / 371$ product ion cluster, since gas phase $\Delta \mathrm{H}^{\circ}$ acid acidity of hydroxyl groups is in the $370-380 \mathrm{kcal} / \mathrm{mol}$ range i.e., relatively close to that of water $\left(\Delta \mathrm{H}^{\circ}{ }_{\text {acid(H2O })}=390.3\right.$ $\mathrm{kcal} / \mathrm{mol}){ }^{84}$ Otherwise, back HDX within the phosphate ester group can be ruled out because of its probable involvement in the non-covalent binding to arginine within the NCC anions. ${ }^{41}$ In contrast, for the $\left.\left[\mathrm{F}_{\mathrm{f}} \mathrm{P}_{\mathrm{d}(6+i)}\right)^{-} \mathrm{D}\right]^{-}$product anion, the charge is likely carried by the phosphate ester group with an acidity roughly equal to $\Delta \mathrm{H}^{\circ}{ }_{\text {(acid) }}=329 \mathrm{kcal} / \mathrm{mol}^{8}{ }^{84}$ Then, back $\mathrm{HDX}$ involving this anion is too endothermic (i.e., $+61.3 \mathrm{kcal} / \mathrm{mol}$ ), and remains hindered in accordance with the experimental observations (Figure 3).

The CID mode is particularly suited for demonstrating exothermic (or athermic) ion/molecule reactions such as back HDX regarding specific product ions. ${ }^{85,86}$ Indeed, their kinetic energy is strongly reduced during ion trap storage (S2 in Supporting Information) in contrast to that of the precursor ions subjected to resonant excitation. However, by applying zero resonant excitation ( $\mathrm{NCE}=0 \%$ ), the relaxation of precursor ions can be reached. Such conditions can be used for exploring the impact of ion relaxation on the selective back HDX. For this purpose, sequential $\mathrm{MS}^{3}$ experiments were carried out by applying $\mathrm{NCE}=0 \%$ at the second sequential stage. The following dissociation transitions: $\mathrm{m} / \mathrm{z}$ $466 \rightarrow \mathrm{m} / \mathrm{z} 466 \rightarrow, \mathrm{m} / \mathrm{z} 466 \rightarrow \mathrm{m} / \mathrm{z} 372 \rightarrow$ and m/z $466 \rightarrow \mathrm{m} / \mathrm{z} 265 \rightarrow$ are reported in Figure 5.

As shown in Figure 3, back HDX from sodiated NCC-d11 precursor ion $(\mathrm{m} / \mathrm{z} 466)$ was not detected in the CID spectrum. In contrast, using $\mathrm{NCE}=0 \%$ for $\mathrm{MS}^{3}$ experiments, isotopologue anions at $\mathrm{m} / \mathrm{z}$ $466 / 465 / 464$ were observed with relative abundances of 70\%/23\%/7\% (Figure 5a). Therefore, back HDX from the sodiated NCC-d11 anions occurs exclusively under ion relaxation conditions with a maximum of two back HDXs.

The selected depleted species at $\mathrm{m} / \mathrm{z} 372$ ion (Figure 5c) undergoes almost one back HDX. In fact, the normalized abundance of $\mathrm{m} / \mathrm{z} 371$ is $36 \%$ whereas that of $\mathrm{m} / \mathrm{z} 370$ is less than $1.5 \%$, suggesting that a second deuteron exchange with $\mathrm{H}_{2} \mathrm{O}$ is in practice not available (or very slow to migrate). Very likely, only one deuterated reactive site of the ion cluster produced by $C_{(3)}$ neutral loss, although weakly acidic, is enough to allow back HDX with residual $\mathrm{H}_{2} \mathrm{O}$. Then, the detection of isotopologue $\mathrm{m} / \mathrm{z}$ $373 / 372 / 371 / 370$ ion cluster in the CID spectrum of $\mathrm{m} / \mathrm{z} 466$ (Figure 3 ) is related to the existence of back HDX (in addition to inter-partner H/D exchange(s)). Each isotopologue product ion of this cluster should undergo one back HDX. In particular, m/z 371 leads to $\mathrm{m} / \mathrm{z} 370$ which is solely related to back HDX and does not produce anymore $\mathrm{m} / \mathrm{z} 369$. On the other hand, the formation of the $\mathrm{m} / \mathrm{z} 372$ and 
$\mathrm{m} / \mathrm{z} 371$ product ions occurs either through unexpected inter-partner H/D exchange(s) followed by the cross-ring cleavages or by back HDX from the produced m/z 373 and m/z 372 ions.

In contrast, the selected $\mathrm{m} / \mathrm{z} 265$ anions (i.e., $\left[\mathrm{FGP}_{\mathrm{d} 7}-\mathrm{D}\right]^{-}$) does not yield any back HDX using $\mathrm{MS}^{3}$ experiments (Figure $5 \mathbf{b}$ ). This supports the previous assumption that $\left[\mathrm{FGP}_{\mathrm{d} 7}-\mathrm{D}\right]^{-}$ions carrying negative charge exclusively on the phosphate ester group, do not undergo back HDX, ion/molecule reaction with residual water being too endothermic.
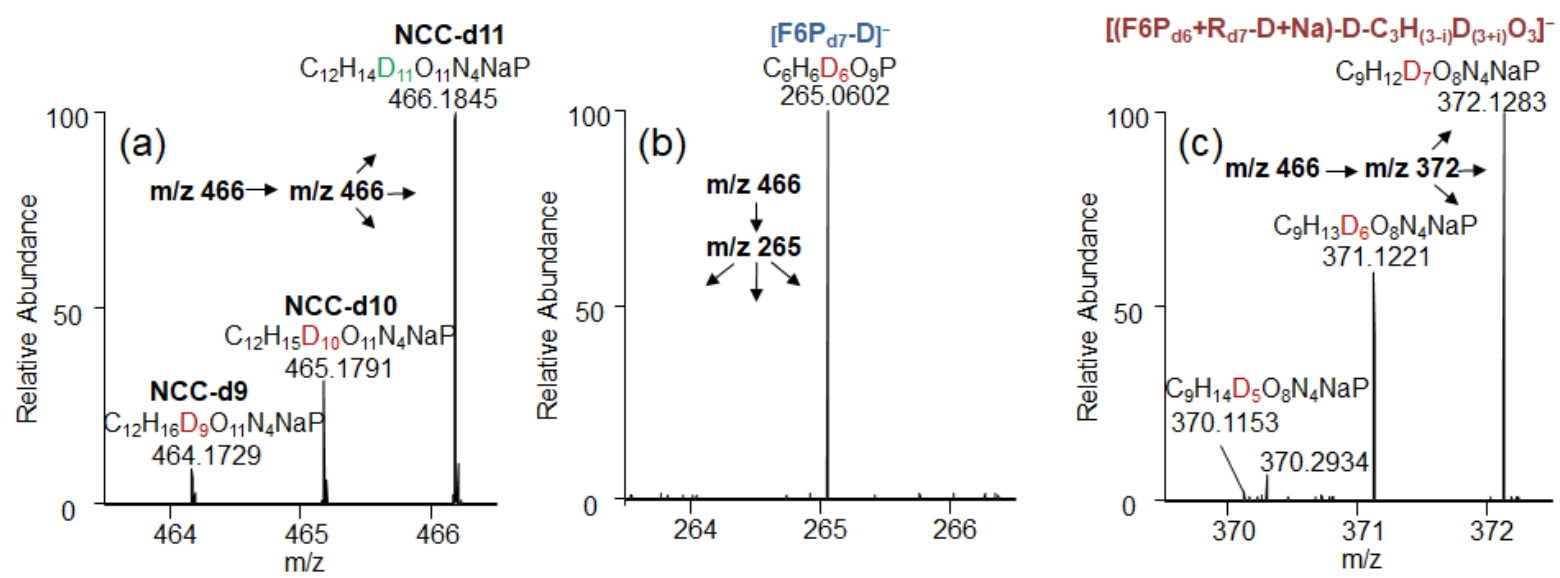

Figure 5. Sequential $M S^{3}$ experiments on the $\left[\left(\mathrm{F}_{6} \mathrm{P}_{\mathrm{d} 6}+\mathrm{R}_{\mathrm{d} 7}-\mathrm{D}+\mathrm{Na}\right)-\mathrm{D}\right]^{-}$precursor ions $(\mathrm{m} / \mathrm{z} 466)$ : the $\mathrm{MS} / \mathrm{MS}$ step (NCE=8\%, ActQ $=0.15$ ) was applied on the $\mathrm{m} / \mathrm{z} 466$ precursor ions followed by the $\mathrm{MS}^{3}$ step (NCE=0\%, ActQ=0.15) on (a) $\mathrm{m} / \mathrm{z}$ 466, (b) $\mathrm{m} / \mathrm{z} 265$ and (c) $\mathrm{m} / \mathrm{z} 372$ ions; optimized ActT value for MS/MS was set at (a) $200 \mathrm{~ms}$ (for maintaining sufficient $\mathrm{m} / \mathrm{z} 466$ abundance to perform sequential $\mathrm{MS}^{3}$ ), (b) and (c) $1000 \mathrm{~ms}$; ActT for $\mathrm{MS}^{3}$ was set at $3000 \mathrm{~ms}$ (only zooms on the ions of interest are reported).

(d) Respective contributions of back HDX and inter-partner H/D exchanges on the observed Denrichment/D-depletion

From the previous observations, a simplified model of the relative contribution of back HDX was deduced and is proposed as evidence of the correlation between D-enrichment ( $\mathrm{m} / \mathrm{z}$ 264/265/266 product ion) and D-depletion (m/z 373/372/371). Indeed, it can be assumed that experimentally detected $\mathrm{m} / \mathrm{z} 373$ results from CB cleavages of sodiated NCC-d11 anions, and that it then undergoes one back HDX with residual light water. Thus, the observed abundance of the $\mathrm{m} / \mathrm{z} 372$ product anions corresponds to the sum of abundances of the $\mathrm{m} / \mathrm{z} 372$ ions solely due to D-depletion (i.e., from one inter-partner H/D exchange) and the $\mathrm{m} / \mathrm{z} 372$ ions from the $\mathrm{m} / \mathrm{z} 373$ due to back HDX. For the observed abundance of $\mathrm{m} / \mathrm{z} 371$, the same approach can be applied, whereas the observed $\mathrm{m} / \mathrm{z}$ 370 abundance should be attributed exclusively to that of the ions generated by back HDX from the $\mathrm{m} / \mathrm{z} 371$ ions which themselves are strictly formed by D-depletion. 
Table 1. Estimation of normalized fraction ${ }^{(a)}$ of isotopologue ions of the $\mathrm{m} / \mathrm{z} 373 / 372 / 371$ (i.e., $\mathrm{i}=0,1$ and 2 ) compared to the normalized fraction of the $\mathrm{m} / \mathrm{z}$ 264/265/266 product ion clusters generated from the sodiated NCC-d11 anion using CID mode at ActT (a) 3000 ms (see Figure 3), (b) 1700 ms, and (c) 100 $\mathrm{ms}$ for the back HDX and inter-partner $\mathrm{H} / \mathrm{D}$ exchanges, respectively (with $\mathrm{ActQ}=0.15, \mathrm{NCE}=8 \%$ ) and (d) at ActT=10 ms from Figure 1 (with $A c t Q=0.25$, $\mathrm{NCE}=13 \%$ ) for estimation of relative contribution of direct NCC partner splitting

\begin{tabular}{|c|c|c|c|c|c|}
\hline $\begin{array}{c}\text { Normalized ion } \\
\text { abundances (\%) } \\
\text { within product ion } \\
\text { cluster }\end{array}$ & $\begin{array}{l}\text { Estimated fraction of } \\
\text { ions resulting from back } \\
\operatorname{HDX}\left(\mathrm{I}_{[373-(i+1)]} * \%\right)\end{array}$ & $\begin{array}{c}\text { Fraction of ions strictly } \\
\text { corresponding to D-depletion } \\
\left(\mathrm{I}_{[373-\mathrm{i}]} \ddagger \%\right)^{(\mathrm{ff})} \text { (no back HDX) }\end{array}$ & $\begin{array}{l}\text { Normalized fraction of ions } \\
\text { only related to D-depletion } \\
\text { (before back HDX) (\%) }\end{array}$ & $\begin{array}{l}\text { Ion cluster } \\
\text { related to D- } \\
\text { enrichment }\end{array}$ & $\begin{array}{l}\text { Normalized fraction of } \\
\text { ions related to D- } \\
\text { enrichment (\%) }\end{array}$ \\
\hline $\mathrm{m} / \mathrm{z} 373(19.3)$ & $0^{(\mathbf{b})}$ & 19.3 & $40.1^{(\mathrm{g})}$ & $\mathrm{m} / \mathrm{z} 264^{(\mathrm{i})}$ & 39.8 \\
\hline $\mathrm{m} / \mathrm{z} 372(41.8)$ & $19.3^{(c)}$ & 22.5 (i.e., 41.8-19.3) & 46.8 & $\mathrm{~m} / \mathrm{z} 265$ & 46.3 \\
\hline $\mathrm{m} / \mathrm{z} 371(28.8)$ & $22.5^{(\mathrm{d})}$ & 6.3 & 13.1 & $\mathrm{~m} / \mathrm{z} 266$ & 13.9 \\
\hline $\mathrm{m} / \mathrm{z} 373(27.3)$ & 0 & 27.3 & 47.8 & $\mathrm{~m} / \mathrm{z} 264^{(\mathrm{i})}$ & 45 \\
\hline $\mathrm{m} / \mathrm{z} 372(46.2)$ & 19.1 & 27.1 & 47.5 & $\mathrm{~m} / \mathrm{z} 265$ & 45 \\
\hline $\mathrm{m} / \mathrm{z} 371(21.7)$ & 19 & 2.7 & 4.7 & $\mathrm{~m} / \mathrm{z} 266$ & 10 \\
\hline $\mathrm{m} / \mathrm{z} 370(4.8)$ & 1.9 & & & & \\
\hline \multicolumn{6}{|c|}{ (c) ActT $=100 \mathrm{~ms}(\alpha=0.03)$} \\
\hline $\mathrm{m} / \mathrm{z} 373$ (63.3) & 0 & 63.3 & 65.2 & $\mathrm{~m} / \mathrm{z} 264^{(\mathrm{i})}$ & $68.8^{(j)}$ \\
\hline $\begin{array}{c}\text { Ion cluster related to } \\
\text { D-depletion }\end{array}$ & $\begin{array}{c}\text { Normalized } \\
\text { abundances due to D- } \\
\text { depletion (\%) without } \\
\text { back HDX }\end{array}$ & $\begin{array}{l}\text { Normalized abundances } \\
(\%) \text { within ion cluster } \\
\text { related to D-enrichment }\end{array}$ & $\begin{array}{l}\text { Estimated fraction (\%) of } \\
\text { ions related to D-enrichment } \\
\text { from splitting of isomerized } \\
\mathrm{NCC}(\mathrm{h})\end{array}$ & \multicolumn{2}{|c|}{$\begin{array}{l}\text { Estimated fraction (\%) of expected } \mathrm{m} / \mathrm{z} 264 \\
\text { ion from splitting prior to isomerization }\end{array}$} \\
\hline $\mathrm{m} / \mathrm{z} 373$ & 64.9 & $\mathrm{~m} / \mathrm{z} 264(74.1)$ & 47.9 & \multicolumn{2}{|r|}{$26.2^{(k)}$} \\
\hline $\mathrm{m} / \mathrm{z} 372$ & 35.1 & $\mathrm{~m} / \mathrm{z} 265$ (25.9) & 25.9 & & \\
\hline
\end{tabular}

(a) The $\mathrm{m} / \mathrm{z} 369$ and $\mathrm{m} / \mathrm{z} 263$ product ions with the maximum normalized abundances of $0.7 \%$ and $2 \%$ at ActT = 3000 ms, respectively, relative to that of 
corresponding ion cluster, were neglected in calculations for product ion cluster abundance normalization (100\%).

(b) According to our data, m/z 373 product ion results, as expected, from CB cleavages of NCC-d11 precursor anions, therefore, no back HDX and no interpartner $<\mathrm{HDX}>$ were considered for this ion.

(c) $\mathrm{Al}_{[373-(i+1)]} *$ value of $19.3 \%$ is the estimated fraction of ions resulting from back HDX of $\mathrm{m} / \mathrm{z} 373$, since the random probability (equal to $1 / 2$ ) to undergo or not back HDX for each isotopologue (373-i) ions is assumed at ActT=3000 ms (factor $\alpha=1$ ).

(d) Similarly, $\mathrm{I}_{[373-(i+1)]} *$ value of $22.5 \%$ is attributed to $\mathrm{m} / \mathrm{z} 372$, considering that $22.5 \%$ of $\mathrm{m} / \mathrm{z} 372$ was obtained from D-depletion without back HDX and assuming that half of $\mathrm{m} / \mathrm{z} 372$ undergoes back HDX at ActT=3000 ms (factor $\alpha=1$ )

(e) $\mathrm{I}_{[373-(i+1)]} *$ value of $6.3 \%$, the same as for the fraction of $\mathrm{m} / \mathrm{z} 371$ only related to $\mathrm{D}$-depletion, considering that about a half of $\mathrm{m} / \mathrm{z} 372$ produced by $\mathrm{D}$ depletion, is subjected to back HDX at ActT=3000 ms (factor $\alpha=1$ ) and the difference with experimental value of 10.1 assumed to be related to experimental error for the smallest peak intensity

(f) $\mathrm{I}_{[373-\mathrm{i}]} \neq$ values obtained by subtracting the fraction related to back HDX from the experimental value of each isotopologue product ion.

(g) Reconstituted normalized abundance of the expected $\mathrm{m} / \mathrm{z} 373$ ion prior to back HDX

(h) Fractions of expected m/z 264 and enriched m/z 265 in correlation with the fractions of expected m/z 373 and depleted $\mathrm{m} / \mathrm{z} 372$ ions (related to the sugar ring $\mathrm{C}_{(3)}$ neutral loss) calculated as $64.9 \times 25.9 / 35.1=47.9(\%)$

(i) Corresponding to direct splitting of partners prior to and after isomerization of sodiated NCC-d11

(j) This $68.8 \%$ value is higher than those expected i.e., $65.2 \%$ from calculation using the D-depletion value. The difference is attributed to the partner splitting (i.e., $3.5 \%$ ) from the sodiated NCC-d11 m/z 466 anion. On the other hand, this means that $5.4 \%$ (value obtained by normalization to 65.2 i e., $3.5 \times 100 / 65.2)$ of the $\mathrm{m} / \mathrm{z} 264$ population are provided from the initial $\mathrm{SSA}_{\mathrm{zw}}$ form and thus, $94.6 \%$ from the isomerized $\mathrm{SSA}_{\mathrm{zw}}$ form.

(k) $74.1-47.9=26.2$ (\%). This corresponds to $35.4 \%$ (value obtained by normalization to 74.1 i.e., $26.2 / 74.1 \times 100$ ) which means that direct splitting occurs for $35.4 \%$ of the $\mathrm{m} / \mathrm{z} 264$ ion population and splitting after isomerization takes place for $64.6 \%$. 
Our calculations (Table 1), first applied to CID experiments at ActT $=3000 \mathrm{~ms}$ and then at ActT=1700 ms and $100 \mathrm{~ms}$, are based on the rough estimation of $\alpha=\mathrm{I}_{\left[373-(i+1)^{*}\right]} / \mathrm{I}_{[373-\mathrm{j}]} \neq$ ratio as back HDX factor (with $\mathrm{i}=0,1$ and 2 ). The abundance of the $\mathrm{m} / \mathrm{z}(373-\mathrm{i})$ ions before any back HDX is noted as $\mathrm{I}_{[373-\mathrm{i}]^{\ddagger}}$. The estimated back HDX contribution of the $\mathrm{m} / \mathrm{z}(373-i)$ ions which only enhances the abundance of the ions produced by D-depletion i.e., $\mathrm{m} / \mathrm{z}[373-(i+1)]$, ions (i.e., $\mathrm{I}_{\left.[373-(i+1)]^{\ddagger}\right)}$ is noted as $\mathrm{I}_{\left[373-(i+1)^{*}\right]}$. Then, according to several iterations based on the previous considerations at ActT=3000 ms, the $\alpha$ value equal to 1 (i.e., a 1/2 random probability undergoing (or not) one back HDX for each isotopologue (373-i) product ions ( $\mathrm{i}=0,1$ and 2$)$ ), is the one which fits the best with the experimental data (Table 1). Afterward, it is possible to recalculate the remaining abundances $\left(\mathrm{I}_{[373-\mathrm{i}]} \ddagger\right)$ of $\mathrm{m} / \mathrm{z}(373-i)$ ion cluster ( $i=0,1$ and 2 ) only due to the D-depletion (as "Fraction of survivor ions strictly corresponding to Ddepletion $\left(\mathrm{l}_{[373-\mathrm{i}]^{]}}\right)^{(\mathrm{f})}$ in the Table 1. These values were further normalized ("Normalized fraction of ions related to D-depletion (before back HDX) (\%)" in the Table 1 i.e., (373-i)) in order to compare them with the experimentally detected normalized abundances of (264+i) ion cluster ('Normalized fraction of ions related to D-enrichment" in the Table 1). Comparison of the corrected and experimentally normalized abundances of the $\mathrm{m} / \mathrm{z} 373 / 372 / 371$ and 264/265/266 ion clusters, demonstrates a good correlation between them (Table 1). This providing a definitive evidence for the unexpected inter-partner H/D exchanges during the sodiated NCC-d11 anion dissociations, resulting in correlated D-enrichment/D-depletion, within experimental errors.

Using such a model and iterative approach, the $\alpha$ factor values of 0.7 and 0.03 are estimated for CID experiments at ActT as $1700 \mathrm{~ms}$ and $100 \mathrm{~ms}$, respectively (Table 1). By applying such $\alpha$ values, correlated normalized abundances between the $\mathrm{m} / \mathrm{z}(373-\mathrm{i})$ and $\mathrm{m} / \mathrm{z}(264+\mathrm{i})$ ion clusters $(\mathrm{i}=0,1$ and 2) were still observed. This gives additional clues of inter-partner $H / D$ exchanges as the isomerization responsible for the formation of unexpected $\mathrm{m} / \mathrm{z}(373-\mathrm{i})$ and $\mathrm{m} / \mathrm{z}(264+\mathrm{i})$ ion clusters ( $\mathrm{i}=0,1$ and 2 ) by cross-ring cleavages through rearrangement in competition with partner splitting. Additionally, calculations in Table 1 provide further insights of different fragmentation patterns and ion/molecule reactions. Below $100 \mathrm{~ms}$, back HDX can be negligible $(\alpha=0,03)$ compared to the $\mathrm{D}$-depletion/Denrichment processes. Indeed, approximately one-third of the $\left[\mathrm{FGP}_{\mathrm{d} 6}-\mathrm{D}\right]^{-}$product ions $(\mathrm{m} / \mathrm{z} 264)$ incorporating one $D$ (ion $\mathrm{m} / \mathrm{z} 265$ ) only results from inter-partner $H / D$ exchange. Under these conditions, a relative contribution of the direct splitting of sodiated NCC-d11 (i.e., prior to any NCC isomerization way) reinforcing to the $\mathrm{m} / \mathrm{z} 264$ population (Scheme 2) becomes non-negligible (see the calculated "estimated fraction of expected m/z 264 ion prior to isomerization" in Table 1).

3. Proposed structures of the $\left[\left(\mathrm{FGP}_{\mathrm{d} 6}+\mathrm{R}_{\mathrm{d} 7}-\mathrm{D}+\mathrm{Na}\right)-\mathrm{D}\right]^{-}$anions and mechanisms of the inter-partner $H / D$ exchanges and dissociation processes 


\section{(a) Unusual hydride/deuteride exchange within NCC anions}

The following results are useful for giving clues on the inter-partner H/D exchange mechanisms resulting in complementary D-depletion/D-enrichment:

- $\quad$ Regarding unexpected D-enrichment, a maximum of two H/D exchanges can be achieved (Figure 3 and Figure 4).

- Similarly, other labeled product ions related to the sugar cross-ring cleavages without non covalent interaction disruption, at $\mathrm{m} / \mathrm{z} 404, \mathrm{~m} / \mathrm{z} 373, \mathrm{~m} / \mathrm{z} 342$ and $\mathrm{m} / \mathrm{z} 300$ (generated by $\mathrm{C}_{(2)}$, $\mathrm{C}_{(3)}, \mathrm{C}_{(4)}$, and $\mathrm{C}_{(6)}$ neutral losses) display mainly loss of 1 or $2 \mathrm{D}$ (Figure 3 ).

- Moreover, the D-depletion, related to the generation of the unexpected $\mathrm{m} / \mathrm{z} 372 / 371$ doublet, is overestimated compared to the D-enrichment (Figure 2 and Figure 4), mainly due to back HDX. Its yield increases with ActT although only one exchange takes place from each isotopologue ions of the $\mathrm{m} / \mathrm{z}(373-i)$ cluster (with $\mathrm{i}=0,1$ and 2 ) and not from $\mathrm{m} / \mathrm{z} 370$, the latter being only the product of back HDX.

- The unique back HDX from this doublet is selective since it does not take place on the competitive $\left[\mathrm{FGP}_{\mathrm{d} 6}-\mathrm{D}\right]^{-}$product anions (Figure 5). Alternatively, back HDX can be observed on the relaxed sodiated NCC-d11 anions under zero resonant excitation conditions (Figure 5). No $H / D$ scrambling was observed highlighting the specificity of the unexpected inter-partner $H / D$ exchanges and the back HDX.

The first and second inter-partner $H / D$ exchange(s) between the $R_{d 7}$ and $F 6 P_{d 6}$ partners yielding $\left[\mathrm{FGP}_{\mathrm{d}(6+i)^{-}}{ }^{-\mathrm{D}}\right]^{-}$(with $\mathrm{i}=1$ and 2 ) should exclusively involve non-labile hydrogen atoms at the CHOD or $\mathrm{CH}_{2} \mathrm{OD}$ groups of $\mathrm{F} 6 \mathrm{P}_{\mathrm{d} 6}$ since all mobilizable protons of $\mathrm{m} / \mathrm{z} 466$ precursor ions are already exchanged (Scheme 1). Consequently, an inter-partner hydride/deuteride exchange (as $<H D X>$ ) must be assumed as a probable rearrangement pathway resulting in the correlated D-enrichment/Ddepletion of product ions. Such $<\mathrm{HDX}>$ processes must take place exclusively through inter-partner red-ox reactions. This may be possible if prior to NCC dissociation, the structure of the complex isomerizes into a form that can allow such red-ox reactions. Such inter-partner <HDXs $>$ occurring within non-covalent complexes have never been described before. However, in some cases, hydride transfers within non-covalent complex ions as intermediates have been previously reported for NCC generated either by gas phase ion/molecule reactions, ${ }^{87-91}$ or by stepwise isomerization of charged molecular species. ${ }^{92-94}$ In addition, hydride transfer during $\mathrm{C}-\mathrm{C}$ and $\mathrm{C}-\mathrm{O}$ bond cleavages for deprotonated species containing primary and secondary alkoxy groups has been reported. ${ }^{95-97}$ Therefore, assuming a negative charge at an $\mathrm{H}_{n} \mathrm{C}^{-} \mathrm{O}^{-}$site $(\mathrm{n}=1$ and 2$)$ of the fructose partner, the sodiated NCC-d11 anion may isomerize by a direct fructose ring opening through the cleavage of the $\mathrm{C}-\mathrm{C}$ bond geminal to the alkoxide site resulting in an aldehyde group at one end and an alkoxide at 
another. ${ }^{73}$ Thus, unexpected D-enrichment/D-depletion can be explained from such an intermediate, provided that inter-partner exchangeable sites are sufficiently close.

(b) Proposed mechanism to rationalize the inter-partner hydride/deuteride exchanges from the sodiated NCC-d11 anions

Quantum calculations on the sodiated NCC anions give some important insights into its gas phase conformation(s) and the proximity of interactive groups of partners. This may support the hypothesis of the hydride/deuteride exchange (as $\langle\mathrm{HDX}>$ ) occurrence. Calculations were performed for the unlabeled HB and both SSA forms (Figure 6, S3 in Supporting Information) and confirmed the proposed folded conformations of the sodiated NCC anions (Scheme 1). However, calculations show that the HB form evolves towards the SSA forms (Figure 6, S3 in Supporting Information).
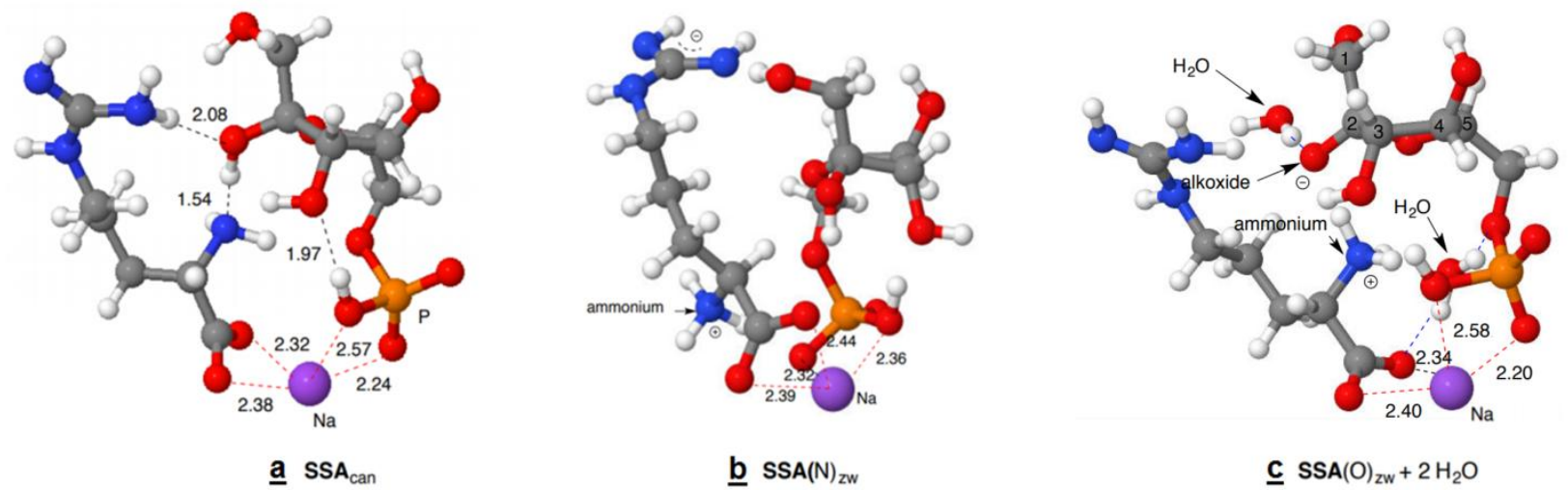

Figure 6. Folded conformations of the sodiated NCC anion within solvated salt forms: (a) canonical

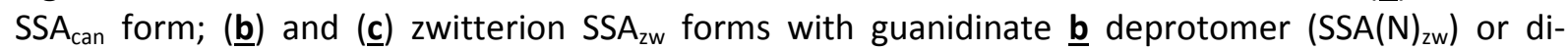
hydrated alkoxide $\underline{\mathbf{c}}$ deprotomer $\left(\mathrm{SSA}(\mathrm{O})_{2 \mathrm{w}}+2 \mathrm{H}_{2} \mathrm{O}\right)$ obtained from quantum calculations (distances in $\AA ̊$, S4 Supporting Information).

The $\underline{a}$ form $\left(\mathrm{SSA}_{\mathrm{can}}\right.$ with the negative charges of the F6P phosphate and the R carboxylate engaged in the $\mathrm{Na}^{+}$solvation, Figure 6 ), more stable than $\mathbf{b}$ form by $41.8 \mathrm{kcal} / \mathrm{mol}$, cannot be involved in the cross-ring processes (formation of $\mathrm{m} / \mathrm{z} \mathrm{m} / \mathrm{z} 373$ for labeled NCC-d11 species) because of the absence of the free charge to promote CB cleavages. Thus, this folded form can exclusively yield $\mathrm{m} / \mathrm{z} 264$ by partner splitting (pathway (a), Scheme 2). On the other hand, in the case of the folded stable $\underline{\mathbf{b}}$ form (i.e., $\mathrm{SSA}(\mathrm{N})_{z w}$, Figure 6), the free negative charge present at the guanidino group can potentially drive proton transfer by endothermic prototropy from spatially adjacent hydroxyl site of fructose. This leads to formation of the $\underline{\mathbf{c}}$ form stabilized by hydration (i.e., $\mathrm{SSA}(\mathrm{O})_{z w}+2 \mathrm{xH}_{2} \mathrm{O}$, Figure 6). In order to compare $\underline{\mathbf{a}}, \underline{\mathbf{b}}$ and $\underline{\mathbf{c}}$ di-hydrated forms, the calculations were also performed on the $\underline{\mathbf{a}}+2 \mathrm{xH}_{2} \mathrm{O}$ and $\underline{\mathbf{b}}+2 \mathrm{xH}_{2} \mathrm{O}$ forms (see Figure $\mathbf{S 5}$ and Text $\mathbf{S 3}$ in Supporting Information). In fact, the di-hydrated $\underline{\mathbf{c}}+2 \mathrm{xH}_{2} \mathrm{O}$ and $\underline{\mathbf{a}}+2 \mathrm{xH}_{2} \mathrm{O}$ forms show comparable stability, since the difference in stability values is reduced to $1.3 \mathrm{kcal} / \mathrm{mol}$ in favor of the dehydrated canonical form (S3 in Supporting Information). To 
simplify the discussion, this hydration has not been considered (except for back HDX). The $\underline{\mathbf{c}}$ form can yield $\mathrm{m} / \mathrm{z}(373-\mathrm{i})$ ( $\mathrm{i}=1$ and 2 ) by cross-ring cleavages, as well as $\mathrm{m} / \mathrm{z}(264+\mathrm{i})(\mathrm{i}=1$ and 2 ) by splitting of partners of sodiated NCC-d11 anions (pathway (c) Scheme 2).

Dissociations of the sodiated NCC anions within form $\underline{\mathbf{c}}$ (Figure 6) with deprotonated anomeric (C-2) hydroxyl site (tertiary alcohol) may lead to the $C_{(2)}$ neutral cluster loss by a stepwise <HDX> (mechanism not discussed). Otherwise, the $\underline{\mathbf{c}}^{\prime}$ form (Scheme 3), with a deprotonated site at C-4 (or C3) position of F6P ( $a$ priori not involved in the non-covalent binding) can be formed by prototropy. ${ }^{73}$ The discussion will be focused on this form that provides the $373 / 372 / 371$ ion cluster. A possible stepwise mechanism for $\underline{\mathbf{c}}^{\prime}$ deprotomer isomerization is proposed in Scheme $\mathbf{3}$. For each intermediate, competitive dissociations (i.e., partner splitting and CB cleavages) can take place.

First, the negative charge of the alkoxide group may promote its C-C vicinal bond cleavage (Scheme 3), resulting in the fructose ring between the C-3 and C-4 being opened concomitantly with a 1-2 deuteron migration ( $\underline{c}^{\prime} \rightarrow \underline{\mathbf{d}}$ sequence, Scheme $\mathbf{3}$ ). Thus, it results in an acyclic chain carrying aldehyde $(-\mathrm{CHO})$ at $\mathrm{C}-4$ end, and deuterated primary alkoxide (i.e., $\left.-\mathrm{CHD}-\mathrm{O}^{-}\right)$at $\mathrm{C}-3$ end. This means that the alkoxide oxidation and the $\mathrm{C}-\mathrm{C}$ bond reduction takes place. ${ }^{71,73}$ Such a $\mathrm{C}-3 / \mathrm{C}-4$ bond cleavage assisted by the negative charge on the vicinal alkoxide at C-4 has already been described especially for fructose-6-phosphate. ${ }^{71,73}$

Next, the folded conformation of the sodiated NCC does allow the (-CHD-O$\left.{ }^{-}\right)$alkoxide site oxidation at $\mathrm{C}-3$ and the aldehyde $(-\mathrm{CHO})$ reduction at $\mathrm{C}-4$. To take place, the $\left(\mathrm{DN}=\mathrm{C}-\left(\mathrm{ND}_{2}\right)\right)$ guanidino group neighboring both the $(\mathrm{H})(\mathrm{D}) \mathrm{C}-\mathrm{O}^{-}$and $(\mathrm{H}) \mathrm{C}=\mathrm{O}$ group ends does play the role of a relay in which $\mathrm{C}=\mathrm{ND}$ is reduced and $\mathrm{C}-\mathrm{ND}_{2}$ is oxidized ( $\underline{\mathbf{d}} \rightarrow \underline{\mathbf{e}}$ sequence, Scheme $\mathbf{3}$ ). In such a redox sequence, the $\langle\mathrm{HDX}>$ pathways are comparable to the relay mechanism of gas phase HDX. ${ }^{98-102}$ This concerted double hydride/deuteride transfer results in stepwise isomerization processes which can take place several times as described in Scheme $\mathbf{3}$ through the $\underline{\mathbf{c}^{\prime}} \rightarrow \underline{\mathbf{d}} \rightarrow \underline{\mathrm{e}} \rightarrow \underline{\mathbf{f}}(\mathbf{g}) \rightarrow \underline{\mathbf{h}}$ sequences. According to the proposed stepwise mechanism, a maximum of two deuteride exchanges became possible leading to the Denrichment of $\mathrm{F} 6 \mathrm{P}_{\mathrm{d} 6}$ in correlation with the D-depletion of its $\mathrm{R}_{\mathrm{d} 7}$ partner (Table 2).

Table 2. Formation of the different labeled [F6P $\left.\left.\mathrm{P}_{\mathrm{d}(6+\mathrm{t})}\right)^{-\mathrm{D}}\right]^{-}$(highlighted in grey) and $\left[\left(\mathrm{F}_{\mathrm{f}} \mathrm{P}_{\mathrm{d} 6}+\mathrm{R}_{\mathrm{d} 7}-\mathrm{D}+\mathrm{Na}\right)-\right.$ $\left.\mathrm{D}-\mathrm{C}_{3} \mathrm{H}_{(3-\mathrm{i})} \mathrm{D}_{(3+i)} \mathrm{O}_{3}\right]^{-}$isotopologue product ions ( $\mathrm{i}=0,1$ and 2 ) according to the Intermediate sodiated NCC anion structures (back HDX from the $\mathrm{m} / \mathrm{z}$ (373-i) product ions is not considered), see Scheme 4

\begin{tabular}{|c|c|c|l|l|}
\hline $\begin{array}{c}\text { Intermediate NCC } \\
\text { anion structures }\end{array}$ & $\begin{array}{c}\text { Partner splitting } \\
\text { with HDX* at }\end{array}$ & $\begin{array}{c}\text { Hydride transfer } \\
\text { mechanisms }\end{array}$ & $\begin{array}{c}\text { Neutral } \\
\text { losses }\end{array}$ & $\begin{array}{c}\text { isotopologue anion } \\
\text { clusters }\end{array}$ \\
\hline \multirow{2}{*}{$\underline{\mathbf{d}}$} & $\mathrm{C}-3$ & & {$\left[\mathrm{R}_{\mathrm{d} 7}-\mathrm{D}+\mathrm{Na}\right]$} & {$\left[\mathrm{F}_{\mathrm{dd}}-\mathrm{D}\right]^{-}, \mathrm{m} / \mathrm{z} 264$} \\
\cline { 2 - 5 } & & $1-2 \mathrm{H}^{-}$or $1-2 \mathrm{D}^{-}$ & $\mathrm{C}_{3} \mathrm{H}_{3} \mathrm{D}_{3} \mathrm{O}_{3}$ & $\mathrm{~m} / \mathrm{z} 373$ \\
\hline
\end{tabular}




\begin{tabular}{|c|c|c|c|c|}
\hline \multirow[b]{2}{*}{$\underline{\mathbf{e}}$} & $\mathrm{C}-4$ & & {$\left[\mathrm{R}_{\mathrm{d} 6}-\mathrm{D}+\mathrm{Na}\right]$} & {$\left[\mathrm{F}^{2} \mathrm{P}_{\mathrm{d} 7}-\mathrm{D}\right]^{-}, \mathrm{m} / \mathrm{z} 265$} \\
\hline & & $\begin{array}{l}1-4 \mathrm{H}^{-} \\
1-4 \mathrm{D}^{-}\end{array}$ & $\begin{array}{l}\mathrm{C}_{3} \mathrm{H}_{3} \mathrm{D}_{3} \mathrm{O}_{3} \\
\mathrm{C}_{3} \mathrm{H}_{2} \mathrm{D}_{4} \mathrm{O}_{3}\end{array}$ & $\begin{array}{l}\mathrm{m} / \mathrm{z} 373 \\
\mathrm{~m} / \mathrm{z} 372\end{array}$ \\
\hline \multirow{2}{*}{$\underline{f}$} & $C-3$ & & {$\left[\mathrm{R}_{\mathrm{d} 5}-\mathrm{D}+\mathrm{Na}\right]$} & {$\left[\mathrm{F} 6 \mathrm{P}_{\mathrm{d} 8}-\mathrm{D}\right]^{-}, \mathrm{m} / \mathrm{z} 266$} \\
\hline & & $1-2 D^{-}$ & $\mathrm{C}_{3} \mathrm{H}_{2} \mathrm{D}_{4} \mathrm{O}_{3}$ & $\mathrm{~m} / \mathrm{z} 372$ \\
\hline \multirow[b]{2}{*}{ g } & C-1 & & {$\left[\mathrm{R}_{\mathrm{d} 5}-\mathrm{D}+\mathrm{Na}\right]$} & {$\left[\mathrm{F}^{2} \mathrm{P}_{\mathrm{d} 8}-\mathrm{D}\right]^{-}, \mathrm{m} / \mathrm{z} 266$} \\
\hline & & $1-2 \mathrm{H}^{-}$ & $\mathrm{C}_{3} \mathrm{H}_{2} \mathrm{D}_{4} \mathrm{O}_{3}$ & $\mathrm{~m} / \mathrm{z} 372$ \\
\hline \multirow[b]{2}{*}{$\underline{\mathbf{h}}$} & C-4 & & {$\left[\mathrm{R}_{\mathrm{d} 5}-\mathrm{D}+\mathrm{Na}\right]$} & {$\left[\mathrm{F} \mathrm{P}_{\mathrm{d} 8}-\mathrm{D}\right]^{-}, \mathrm{m} / \mathrm{z} 266$} \\
\hline & & $\begin{array}{l}1-4 \mathrm{H}^{-} \\
1-4 \mathrm{D}^{-}\end{array}$ & $\begin{array}{l}\mathrm{C}_{3} \mathrm{H}_{2} \mathrm{D}_{4} \mathrm{O}_{3} \\
\mathrm{C}_{3} \mathrm{HD}_{5} \mathrm{O}_{3}\end{array}$ & $\begin{array}{l}\mathrm{m} / \mathrm{z} 372 \\
\mathrm{~m} / \mathrm{z} 371\end{array}$ \\
\hline
\end{tabular}

* For the $\mathrm{d}$ form, it is an intra partner hydride/deuteride exchange $(<\mathrm{HDX}\rangle)$

${ }^{\S}$ Intra fructose $\langle\mathrm{HDX}\rangle$

Afterwards, competitive dissociations of the $\underline{\mathbf{d}}, \underline{\mathbf{e}}, \underline{\mathbf{f}}$ (or $\mathbf{g})$, and $\underline{\mathbf{h}}$ NCC intermediates lead to either partner splitting or CB cleavages. Splitting does consist of a partner separation with a deuteron transfer from the $\mathrm{d} 3$-ammonium $\left(\mathrm{ND}_{3}{ }^{+}\right.$) site to the alkoxide (at $\mathrm{C}-1, \mathrm{C}-3$ or $\mathrm{C}-4$ position, according to the considered intermediate, Scheme 3). Alternatively, the $\mathrm{C}_{3} \mathrm{H}_{(3-\mathrm{i})} \mathrm{D}_{(3+i)} \mathrm{O}_{3}$ neutral cluster release is based on the hemiketal (DO)C-O covalent bond cleavage from the opened ring intermediates (i.e., $\underline{\mathbf{d}}$, $\underline{\mathbf{e}}, \underline{\mathbf{f}}(\operatorname{or} \mathbf{g})$ and $\underline{\mathbf{h}})$. Such a CB cleavage is induced by hydride or/and deuteride transfer via either a 1-2 mechanism (for the $\underline{\mathbf{d}}$ and $\underline{\mathbf{f}}$ (or $\mathbf{g}$ ) intermediates) or a 1-4 mechanism (for $\underline{\mathbf{e}}$, and $\underline{\mathbf{h}}$ ) from the primary alkoxide to the hemiketal carbon (C-2, see the proposed mechanisms in Scheme 4). The Table 1 shows different $\left[\mathrm{F}_{6} \mathrm{P}_{\mathrm{d}(6+i)}-\mathrm{D}\right]^{-}$and $\left[\left(\mathrm{F}_{\mathrm{f}} \mathrm{P}_{\mathrm{d}(6+\mathrm{i})}+\mathrm{R}_{\mathrm{d}(7-\mathrm{i})}-\mathrm{D}+\mathrm{Na}\right)-\mathrm{D}-\mathrm{C}_{3} \mathrm{H}_{3-\mathrm{i}} \mathrm{D}_{3+i} \mathrm{O}_{3}\right]^{-}$(with $\mathrm{i}=0,1$ and 2) isotopologue product ions with their respective mechanisms and origins from the different isomerized sodiated NCC intermediates. 

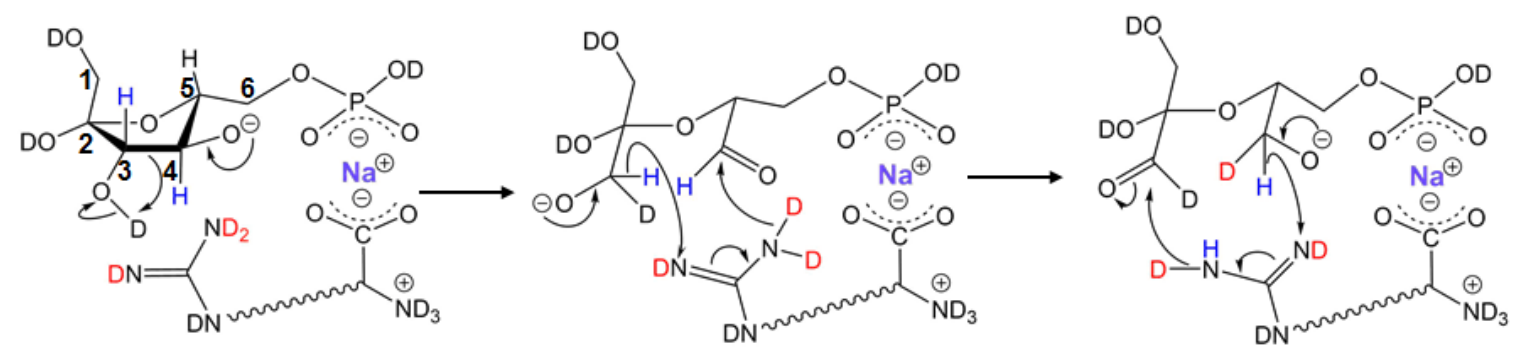

$$
\underline{c}^{\prime}\left[\left(F 6 P_{d 6}+R_{d 7}-D+N a\right)-D\right]^{-}
$$

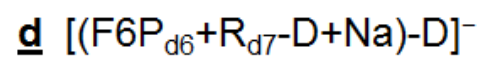

e $\left[\left(F 6 P_{d 7}+R_{d 6}-D+N a\right)-D\right]^{-}$<smiles>[2H]C([2H])([2H])C([2H])([2H])C([2H])([2H])C(=O)NNC(=N)C(=O)O</smiles>

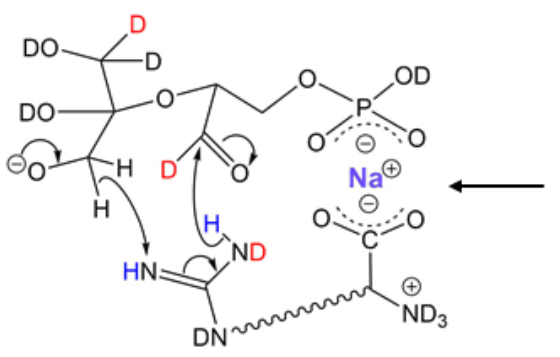

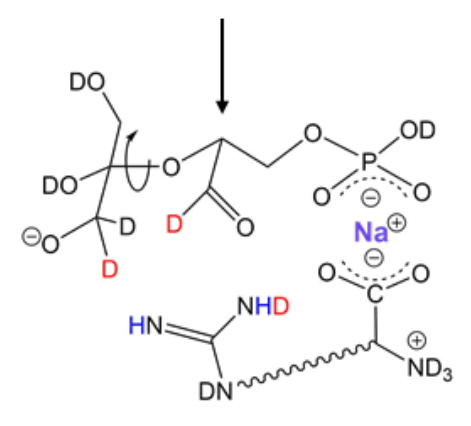

\section{$\underline{\text { h }}\left[\left(\mathrm{F} 6 \mathrm{P}_{\mathrm{d} 8}+\mathrm{R}_{\mathrm{d} 5}-\mathrm{D}+\mathrm{Na}\right)-\mathrm{D}\right]^{-}$}

g $\left[\left(F 6 P_{d 8}+R_{d 5}-\mathrm{D}+\mathrm{Na}\right)-\mathrm{D}\right]^{-}$

f $\left[\left(F 6 P_{d 8}+R_{d 5}-D+N a\right)-D\right]^{-}$

Scheme 3. Proposed stepwise isomerization mechanism for the unexpected $<H D X>$ : sugar ring cleavage of the reactive $\left[\left(F 6 P_{d 6}+R_{d 7}-D+N a\right)-D\right]^{-}$complex $\left(\underline{c}^{\prime} \rightarrow \underline{\mathbf{d}}\right.$ sequence) and inter-partner hydride/deuteride exchanges by consecutive redox reactions between the opened fructose ring and persistent guanidino group of arginine through the isomerized $\left[\left(F 6 P_{d(6+i)}+R_{d(7-i)}-D+N a\right)-D\right]^{-}$ intermediates ( $\underline{\mathbf{d}} \rightarrow \underline{\mathbf{e}}, \underline{\mathbf{e}} \rightarrow \underline{\mathbf{f}}(\mathbf{g})$ and $\mathbf{g} \rightarrow \underline{\mathbf{h}}$ sequences), note that in $\underline{\mathbf{f}} \rightarrow \mathbf{g}$ sequence a free rotation takes place and D-migration from primary hydroxyl group to alkoxide.

\section{(d) Proposed mechanism of selective one back HDX from the $\mathrm{m} / \mathrm{z}$ (373-i) product ions}

As already pointed out, experimental results were rationalized by the unexpected hydride/deuteride exchanges within sodiated NCC-d11 anions due to isomerization processes, providing the formation of both the $\mathrm{m} / \mathrm{z}(373-\mathrm{i})$ and $\mathrm{m} / \mathrm{z}(264+\mathrm{i})$ product ion clusters ( $\mathrm{i}=0,1$ and 2 ). In addition, selective back HDX from $\mathrm{m} / \mathrm{z}(373-i)$ were demonstrated. Therefore, $r_{2}$ ratio reflects the D-depletion reinforced by one selective back HDX. Calculations in Table 1 suggested a maximum probability of 50/50 for exchanging one deuteron with residual light water at maximum ActT=3000 ms, lowered by decreasing the ActT. Such an observation may be rationalized through the dissociation mechanisms leading to the $\mathrm{m} / \mathrm{z}$ (373-i) ion cluster ( $\mathrm{i}=0,1$ and 2 ). 


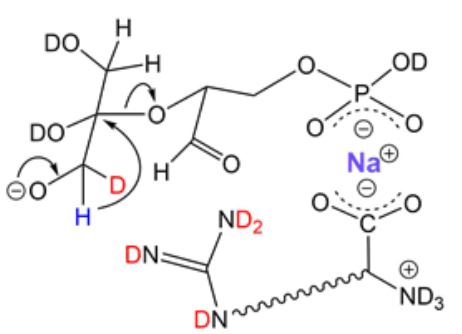

$\underline{\mathbf{d}}$

$$
\mathrm{m} / \mathrm{z} 466
$$

g $1-2 \stackrel{\ominus}{ } \mathrm{H}^{\text {transfer }}$
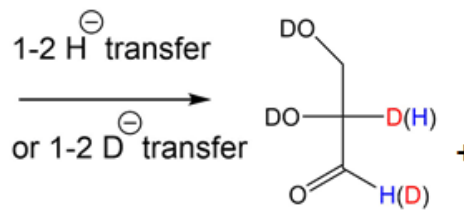

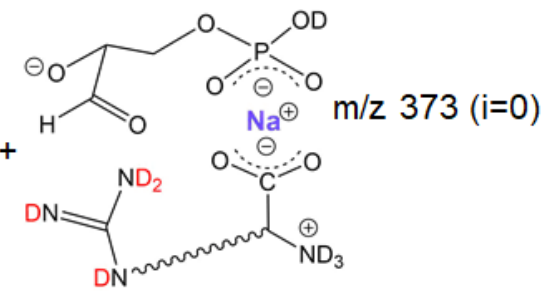

m/z $372(i=1)$

f or $1-2 D^{\ominus}$ transfer

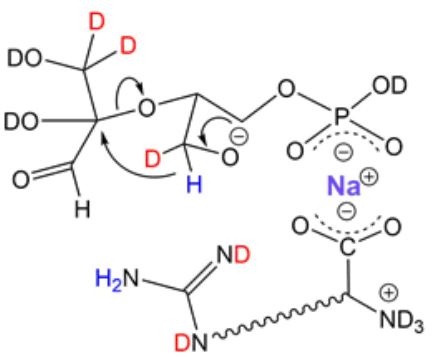

$\underline{\text { h }}$

$\mathrm{m} / \mathrm{z} 466$

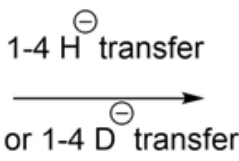<smiles>[2H]C([2H])([2H])C([2H])([18OH])C([2H])([2H])[O-]</smiles>

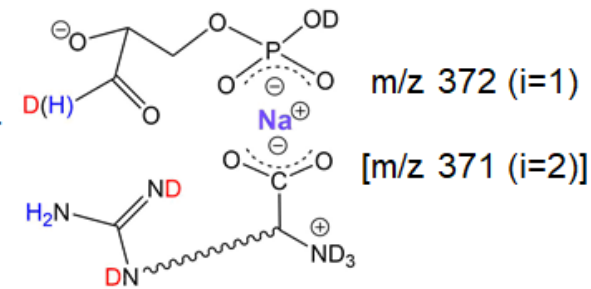

Scheme 4. Proposed mechanisms of the labeled " $C_{(3)}$ " neutral losses with competitive hydride/deuteride transfers (as 1-2 and 1-4 transfer from the $\underline{\mathbf{d}}$ and $\underline{\mathbf{h}}$ isomeric NCC forms, respectively) concomitant with $\mathrm{C}-\mathrm{O}$ bond reduction to yield the isotopologue $\mathrm{m} / \mathrm{z} 373 / 372 / 371$ ion cluster without considering any back HDX.

According to the proposed mechanisms, dissociations of different sodiated NCC-d11 isomerized structures (Scheme 3) provide (through 1-2 $\mathrm{H}^{-} / \mathrm{D}^{-}$and/or 1-4 $\mathrm{H}^{-} / \mathrm{D}^{-}$migrations) the $\mathrm{m} / \mathrm{z}(373-\mathrm{i})$ product ion clusters with retention of the salt solvated interactions. These product ions are within zwitterion forms characterized by free charges at the alkoxide and d3-ammonium groups (Scheme 4). Then, back HDX with residual light water may occur with such ZW structures. Nevertheless, considering a folded conformation of such sodiated NCC product ions, free charges carried by these sites are certainly "quenched" by direct prototropy resulting in canonical forms (as proposed in Scheme 5a), thus hindering further back HDX. Indeed, as shown by calculations, the prototropy process (proton migration from the ammonium group to the alkoxide) occurs without intermediate (Figure 7a). 
(a)

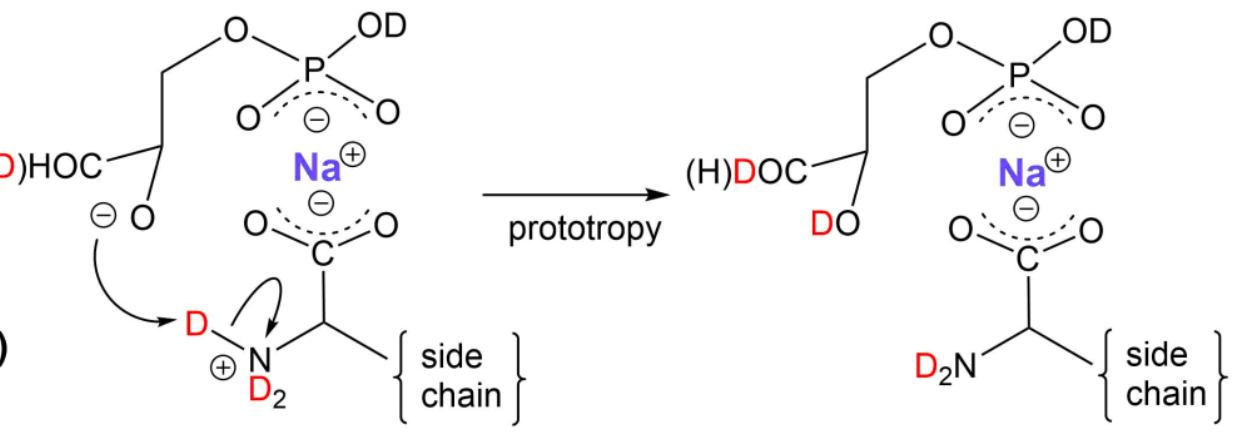

(D)

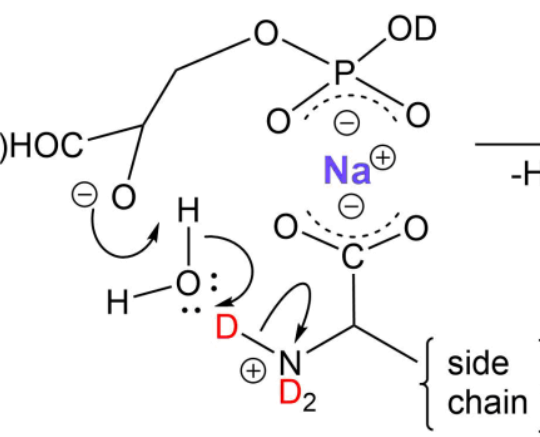<smiles>CC(COP(=O)([O-])OCC(O)C(=O)O)C(=O)O</smiles>

Scheme 5. Proposed mechanisms from the isotopologue $\mathrm{m} / \mathrm{z} 373 / 372 / 371$ ion cluster based on (a) a direct charge neutralization preventing back $\mathrm{HDX}$ and (b) a relay-like process involving $\mathrm{H}_{2} \mathrm{O}$ molecule yielding a specific back $H / D$ exchange (only the interactive groups involved in these processes are represented for better clarity of the scheme)

Alternatively, the ion/molecule reaction with a light water molecule was investigated using calculations (Figure 7b), which showed the hydration of alkoxide through the hydrogen bonding due to the close alcohol/water gas phase acidities. ${ }^{103}$ By refolding, the light water oxygen gets close to the d3-ammonium group. Naturally, the deuteron may migrate to the neighboring water molecule which concomitantly transfers to the alkoxide site its proton which is engaged in hydrogen bonding as shown by calculations (Figure $\mathbf{7 b}$ ). This process can be described as a relay-like mechanism involving water interaction with free charges of product ions within the zwitterion form (Scheme $\mathbf{5 b}$ ). Thus, one deuteron is formally exchanged by a proton on another site, and both the free positive and negative charges are quenched yielding a canonical form (Scheme 5b). This charge neutralization allows a fast detachment of HDO thus hindering the reversibility of the reaction or any additional hydration step which would favor a second H/D exchange. Finally, the proposed mechanisms (Scheme 5) may explain why a part of the $\mathrm{m} / \mathrm{z}$ (373-i) isotopologue ion population does not exchange with water (prototropy into canonical forms) whereas the other part provides only one back HDX (relay-like mechanism) which is enhanced with the ActT increase. 
(a)

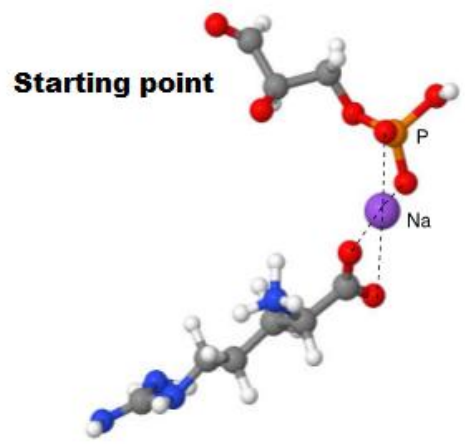

Optimized structure

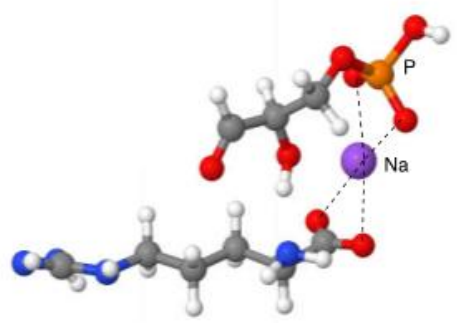

(b)

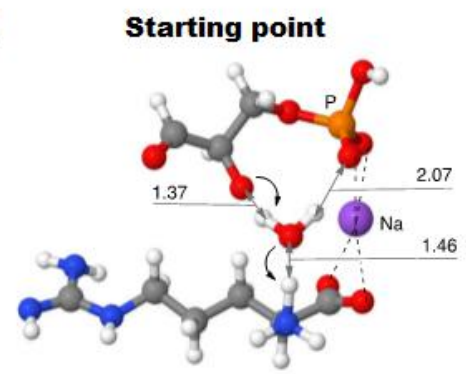

Just after proton transfer

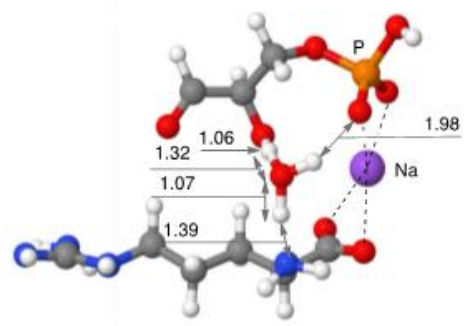

Optimized structure

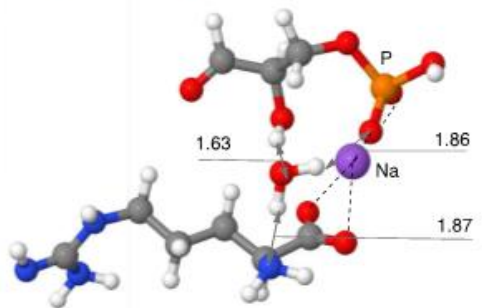

Figure 7. Evolution of conformation of the $\mathrm{m} / \mathrm{z}(373-i)$ fragment ions toward proton (or deuteron) transfer to reach the canonical form: (a) direct internal proton transfer, and (b) relay mechanism involving one water molecule resulting in one back HDX (distances between implied proton and $\mathrm{O} / \mathrm{N}$ atoms are given in $\AA$ )

\section{Conclusion}

Non-covalent (NC) interactions between phosphorylated molecules and proteins' basic amino acid residues are ubiquitous in biological systems such as $G$ protein receptors heteromers. ${ }^{104}$ To understand the charge role in these interactions, NCC heterodimer anions formed by fructose-6phosphate (F6P) and arginine (R) were investigated using ESI MS in negative ion mode $\left\{[\mathrm{F} 6 \mathrm{P}+\mathrm{R}-\mathrm{H}]^{-}\right.$ and $[(\mathrm{F} 6 \mathrm{P}+\mathrm{R}-\mathrm{H}+\mathrm{Na})-\mathrm{H}]^{-}$\}. We focused on the sodiated NCC anions. Product ion spectra recorded under collisional activation conditions, mainly showed partner splitting ([F6P-H $]^{-}$as main peak) and, to a lesser extent, cross-ring cleavages with $\mathrm{Na}^{+}$retention and without affecting the non-covalent interaction. The charge-solvated structure (i.e., $\mathrm{Na}^{+}$solvated by heteroatom electron lone-pairs) was ruled out as its fragmentation should not lead to $\mathrm{Na}^{+}$retention in the product ions. Then, a salt (SA) form can be considered. Therefore, one partner should be a zwitterion with the negative charge involved in ion-ion interaction with $\mathrm{Na}^{+}$. Based on these criteria, quantum calculation demonstrated that the NCC anion conformation is folded and the (HB) form (with free salt) evolves mainly toward a solvated salt (SSA). These forms are within canonical $\left(\mathrm{SSA}_{\mathrm{can}}\right)$ and $\mathrm{ZW}\left(\mathrm{SSA}_{\mathrm{zw}}\right)$ structures. In the folded conformation of SSA, the guanidino group is close to an $\mathrm{OH}$ group of fructose. Only the $\mathrm{SSA}_{\mathrm{zw}}$ form is 
able to promote covalent bond cleavages (i.e., cross-ring process) due to the presence of a free charge without involving the NC interaction, although the $\mathrm{HB}$ and $\mathrm{SSA}_{\text {can }}$ as well as $\mathrm{SSA}_{z w}$ forms can result in the splitting of partners.

To rationalize the possible relationship between cross-ring cleavages and partner splitting, "in solution" D-labeling (HDX) of mobile protons of interactive partners was used resulting in labeled ${ } 6 P_{d 6}$ and $R_{d 7}$. These species yielded the desorbed $\left[\left(F 6 P_{d 6}+R_{d 7}-D+N a\right)-D\right]^{-} N C C$ anions, while under resonant excitation conditions (CID mode), sodiated NCC-d11 anions dissociate into the $\mathrm{m} / \mathrm{z}[264+\mathrm{i}]^{-}$ and $\mathrm{m} / \mathrm{z}$ [373-i] ${ }^{-}$product ion clusters (with $\mathrm{i}=0,1$ and 2 ), which reflects an unexpected $\mathrm{D}$-enrichment and a D-depletion, respectively. By increasing the ActT activation time from $10 \mathrm{~ms}$ to $3000 \mathrm{~ms}$, the $\mathrm{m} / \mathrm{z}[373-\mathrm{i}]^{-}$cluster produced by cross-ring cleavages becomes more abundant than the $\mathrm{m} / \mathrm{z}[264+\mathrm{i}]^{-}$ cluster resulting from partner splitting. The discrepancy between D-enrichment and D-depletion is impacted by a back HDX with residual $\mathrm{H}_{2} \mathrm{O}$ that occurs selectively from each isotopologue ion of the $\mathrm{m} / \mathrm{z}[373-\mathrm{i}]^{-}$ion cluster. Quantum calculations elucidated why this back HDX was limited to one exchange in sequential $\mathrm{MS}^{3}$ experiments with $3000 \mathrm{~ms}$ ion storage without excitation. After correcting the contribution of a "one time" back HDX (reinforced with higher ActT), a good correlation between the D-enrichment and D-depletion, although limited to $2 \mathrm{H} / \mathrm{D}$ exchanges, was obtained. A stepwise dissociation mechanism based on a sodiated NCC-d11 anion isomerization (starting from the F6P ring opening) prior to dissociations was proposed. The isomerized intermediate evolves toward an inter-partner hydride/deuteride $(\langle\mathrm{HDX}\rangle)$ exchange step through a relay-like mechanism described for the first time. Moreover, the intermediate of each sequence-end can dissociate competitively following $\langle\mathrm{HDX}\rangle$. Intermediate dissociations can proceed either by cross-ring cleavages or by partner splitting. This leads to an unexpected D-enrichment/D-depletion with a maximum of two exchanges. It is the first time that specific inter-partner $\mathrm{H}^{-} / \mathrm{D}^{-}$exchanges and a selective back $\mathrm{H}^{+} / \mathrm{D}^{+}$exchange, without randomization with residual light water, are reported for such NCCs.

Future study of other cationized $\mathrm{NCC}$ (with $\mathrm{Na}^{+}$and $\mathrm{Mg}^{++}$) involving hexose phosphate isomers and arginine residues (or arginine containing peptides) as partners will be undertaken in order to establish the structural effects on the occurrence of such unexpected hydride/deuteride exchanges under resonant excitation conditions. 
For table of content only:

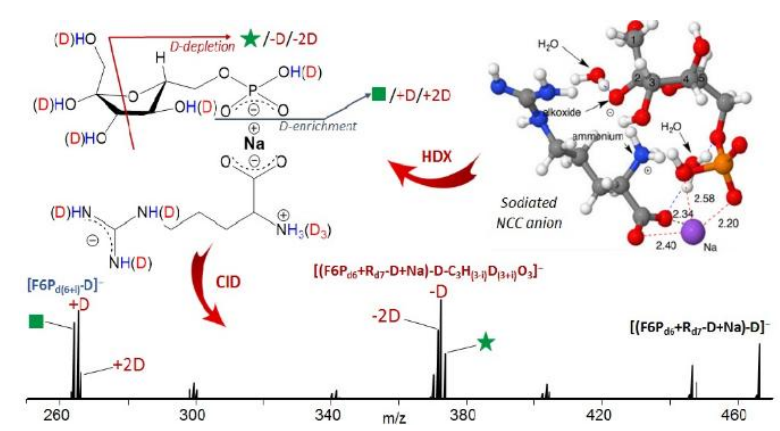

\section{ASSOCIATED CONTENT}

\section{Supporting Information}

Additional information as noted in text. The Supporting Information is available free of charge on the ACS Publications website at DOI: XXX

Figures S1-S6, Table S1, comparison of resonant (CID) and non-resonant (HCD) activation modes (Texts S1 and S2), Quantum Calculations (Texts S3) and computational details (Text S4).

\section{Acknowledgements}

This work was supported by the Commissariat à l'Energie Atomique et aux Energies Alternatives, the MetaboHUB infrastructure (ANR-11-INBS-0010 grant), and cecic-ciment cluster from UGA for calculation.

\section{AUTHOR INFORMATION}

\section{Corresponding Authors}

Darii E., ' Génomique Métabolique, Genoscope, Institut François Jacob, CEA, CNRS, Univ Evry, Université Paris-Saclay, 91057 Evry, France ; orcid.org/0000-0001-7129-8842; E-mail : edariy@genoscope.cns.fr; *Phone : +33607953908

Tabet J.-C., 'Sorbonne Université, Faculté des Sciences et de I'Ingénierie, Institut Parisien de Chimie Moléculaire (IPCM), F-75005 Paris, France; ${ }^{4}$ Université Paris-Saclay, CEA, INRAE, Département Médicaments et Technologies pour la Santé (DMTS), MetaboHUB, F-91191 Gif sur Yvette, France ; orcid.org/0000-0003-0080-2946; E-mail : jean-claude.tabet@courriel.upmc.fr; *Phone: +33 61875 0181

\section{Author contributions}

The manuscript was written through contributions of all authors.

\section{Notes}


The authors declare no competing financial interest 


\section{References}

(1) Strittmatter, E. F.; Schnier, P. D.; Klassen, J. S.; Williams, E. R. Dissociation Energies of Deoxyribose Nucleotide Dimer Anions Measured Using Blackbody Infrared Radiative Dissociation. J. Am. Soc. Mass Spectrom. 1999, 10 (11), 1095-1104. https://doi.org/10.1016/S1044-0305(99)00087-2.

(2) Gabelica, V.; De Pauw, E. Comparison between Solution-Phase Stability and Gas-Phase Kinetic Stability of Oligodeoxynucleotide Duplexes. J. Mass Spectrom. 2001, 36 (4), 397-402. https://doi.org/10.1002/jms.141.

(3) Gidden, J.; Baker, E. S.; Ferzoco, A.; Bowers, M. T. Structural Motifs of DNA Complexes in the Gas Phase. Int. J. Mass Spectrom. 2005, 240 (3), 183-193. https://doi.org/10.1016/j.ijms.2004.09.011.

(4) Schug, K.; Lindner, W. Using Electrospray Ionization-Mass Spectrometry/tandem Mass Spectrometry and Small Molecules to Study Guanidinium-anion Interactions. Int. J. Mass Spectrom. 2005, 241 (1), 11-23. https://doi.org/10.1016/j.ijms.2004.10.019.

(5) Schug, K. A.; Lindner, W. Noncovalent Binding between Guanidinium and Anionic Groups: Focus on Biological- and Synthetic-Based Arginine/guanidinium Interactions with Phosph[on]ate and Sulf[on]ate Residues. Chem. Rev. 2005, 105 (1), 67-114. https://doi.org/10.1021/cr040603j.

(6) Loo, J. A. Studying Noncovalent Protein Complexes by Electrospray lonization Mass Spectrometry. Mass Spectrom. Rev. 1997, 16 (1), 1-23. https://doi.org/10.1002/(SICI)10982787(1997)16:1<1::AID-MAS1>3.0.CO;2-L.

(7) Yin, S.; Xie, Y.; Loo, J. A. Mass Spectrometry of Protein-Ligand Complexes: Enhanced Gas-Phase Stability of Ribonuclease-Nucleotide Complexes. J. Am. Soc. Mass Spectrom. 2008, 19 (8), 11991208. https://doi.org/10.1016/j.jasms.2008.05.012.

(8) Woods, A. S.; Moyer, S. C.; Jackson, S. N. Amazing Stability of Phosphate-Quaternary Amine Interactions. J. Proteome Res. 2008, 7 (8), 3423-3427. https://doi.org/10.1021/pr8001595.

(9) Yamauchi, O. Noncovalent Interactions in Biocomplexes. Phys. Sci. Rev. 2016, 1 (4). https://doi.org/10.1515/psr-2016-0001.

(10) Di Tullio, A.; Reale, S.; De Angelis, F. Molecular Recognition by Mass Spectrometry. J. Mass Spectrom. JMS 2005, 40 (7), 845-865. https://doi.org/10.1002/jms.896.

(11) Martinez, J. A.; Xiao, Q.; Zakarian, A.; Miller, B. G. Antidiabetic Disruptors of the GlucokinaseGlucokinase Regulatory Protein Complex Reorganize a Coulombic Interface. Biochemistry (Mosc.) 2017, 56 (24), 3150-3157. https://doi.org/10.1021/acs.biochem.7b00377.

(12) Lucumí-Moreno, A.; Calcagno, M. L. On the Functional Role of Arg172 in Substrate Binding and Allosteric Transition in Escherichia Coli Glucosamine-6-Phosphate Deaminase. Arch. Biochem. Biophys. 2005, 442 (1), 41-48. https://doi.org/10.1016/j.abb.2005.08.002.

(13) Schurmann, M.; Sprenger, G. A. Fructose-6-Phosphate Aldolase Is a Novel Class I Aldolase from Escherichia Coli and Is Related to a Novel Group of Bacterial Transaldolases. J. Biol. Chem. 2001, 276 (14), 11055-11061. https://doi.org/10.1074/jbc.M008061200.

(14) Valdez, B. C.; French, B. A.; Younathan, E. S.; Chang, S. H. Site-Directed Mutagenesis in Bacillus Stearothermophilus Fructose-6-Phosphate 1-Kinase. Mutation at the Substrate-Binding Site Affects Allosteric Behavior. J. Biol. Chem. 1989, 264 (1), 131-135.

(15) Woods, A. S.; Ferré, S. Amazing Stability of the Arginine-Phosphate Electrostatic Interaction. J. Proteome Res. 2005, 4 (4), 1397-1402. https://doi.org/10.1021/pr050077s.

(16) Li, L.; Vorobyov, I.; Allen, T. W. The Different Interactions of Lysine and Arginine Side Chains with Lipid Membranes. J. Phys. Chem. B 2013, 117 (40), 11906-11920. https://doi.org/10.1021/jp405418y.

(17) Loo, R. R. O.; Loo, J. A. Salt Bridge Rearrangement (SaBRe) Explains the Dissociation Behavior of Noncovalent Complexes. J. Am. Soc. Mass Spectrom. 2016, 27 (6), 975-990. https://doi.org/10.1007/s13361-016-1375-3. 
(18) Strittmatter, E. F.; Williams, E. R. The Role of Proton Affinity, Acidity, and Electrostatics on the Stability of Neutral versus Ion-Pair Forms of Molecular Dimers. Int. J. Mass Spectrom. 2001, 212 (1-3), 287-300. https://doi.org/10.1016/S1387-3806(01)00475-4.

(19) Seo, J.; Hoffmann, W.; Warnke, S.; Bowers, M. T.; Pagel, K.; von Helden, G. Retention of Native Protein Structures in the Absence of Solvent: A Coupled Ion Mobility and Spectroscopic Study. Angew. Chem. Int. Ed Engl. 2016, 55 (45), 14173-14176. https://doi.org/10.1002/anie.201606029.

(20) Morgner, N.; Schmidt, C.; Beilsten-Edmands, V.; Ebong, I.-O.; Patel, N. A.; Clerico, E. M.; Kirschke, E.; Daturpalli, S.; Jackson, S. E.; Agard, D.; Robinson, C. V. Hsp70 Forms Antiparallel Dimers Stabilized by Post-Translational Modifications to Position Clients for Transfer to Hsp90. Cell Rep. 2015, 11 (5), 759-769. https://doi.org/10.1016/j.celrep.2015.03.063.

(21) Kebarle, P.; Verkerk, U. H. Electrospray: From lons in Solution to lons in the Gas Phase, What We Know Now. Mass Spectrom. Rev. 2009, 28 (6), 898-917. https://doi.org/10.1002/mas.20247.

(22) Pramanik, B. N.; Bartner, P. L.; Mirza, U. A.; Liu, Y. H.; Ganguly, A. K. Electrospray lonization Mass Spectrometry for the Study of Non-Covalent Complexes: An Emerging Technology. J. Mass Spectrom. 1998, 33 (10), 911-920. https://doi.org/10.1002/(SICI)10969888(1998100)33:10<911::AID-JMS737>3.0.CO;2-5.

(23) Gabelica, V.; Rosu, F.; De Pauw, E. A Simple Method to Determine Electrospray Response Factors of Noncovalent Complexes. Anal. Chem. 2009, 81 (16), 6708-6715. https://doi.org/10.1021/ac900785m.

(24) Boeri Erba, E.; Barylyuk, K.; Yang, Y.; Zenobi, R. Quantifying Protein-Protein Interactions within Noncovalent Complexes Using Electrospray lonization Mass Spectrometry. Anal. Chem. 2011, 83 (24), 9251-9259. https://doi.org/10.1021/ac201576e.

(25) Meot-Ner (Mautner), M. The lonic Hydrogen Bond. Chem. Rev. 2005, 105 (1), 213-284. https://doi.org/10.1021/cr9411785.

(26) Meot-Ner Mautner, M. Update 1 of: Strong lonic Hydrogen Bonds. Chem. Rev. 2012, 112 (10), PR22-103. https://doi.org/10.1021/cr200430n.

(27) Jia, B.; Angel, L. A.; Ervin, K. M. Threshold Collision-Induced Dissociation of Hydrogen-Bonded Dimers of Carboxylic Acids. J. Phys. Chem. A 2008, 112 (8), 1773-1782. https://doi.org/10.1021/jp7114093.

(28) Mc Luckey, S. A.; Glish, G. L.; Cooks, R. G. Kinetic Energy Effects in Mass Spectrometry/mass Spectrometry Using a Sector/quadrupole Tandem Instrument. Int J Mass Spectrom Ion Phys 1981, 39, 219-231.

(29) Cooks, R. G.; Patrick, J. S.; Kotiaho, T.; McLuckey, S. A. Thermochemical Determinations by the Kinetic Method. Mass Spectrom. Rev. 1994, 13 (4), 287-339. https://doi.org/10.1002/mas.1280130402.

(30) Price, W. D.; Jockusch, R. A.; Williams, E. R. Is Arginine a Zwitterion in the Gas Phase? J. Am. Chem. Soc. 1997, 119 (49), 11988-11989. https://doi.org/10.1021/ja9711627.

(31) Bush, M. F.; O'Brien, J. T.; Prell, J. S.; Saykally, R. J.; Williams, E. R. Infrared Spectroscopy of Cationized Arginine in the Gas Phase: Direct Evidence for the Transition from Nonzwitterionic to Zwitterionic Structure. J. Am. Chem. Soc. 2007, 129 (6), 1612-1622. https://doi.org/10.1021/ja066335j.

(32) Wyttenbach, T.; Witt, M.; Bowers, M. T. On the Question of Salt Bridges of Cationized Amino Acids in the Gas Phase: Glycine and Arginine. Int. J. Mass Spectrom. 1999, 182-183, 243-252. https://doi.org/10.1016/S1387-3806(98)14255-0.

(33) Julian, R. R.; Beauchamp, J. L. Selective Molecular Recognition of Arginine by Anionic Salt Bridge Formation with Bis-Phosphate Crown Ethers: Implications for Gas Phase Peptide Acidity from Adduct Dissociation. J. Am. Soc. Mass Spectrom. 2004, 15 (4), 616-624. https://doi.org/10.1016/j.jasms.2003.12.015. 
(34) Schnier, P. D.; Klassen, J. S.; Strittmatter, E. F.; Williams, E. R. Activation Energies for Dissociation of Double Strand Oligonucleotide Anions: Evidence for Watson-Crick Base Pairing in Vacuo. J. Am. Chem. Soc. 1998, 120 (37), 9605-9613. https://doi.org/10.1021/ja973534h.

(35) Heiles, S.; Berden, G.; Oomens, J.; Williams, E. R. Competition between Salt Bridge and NonZwitterionic Structures in Deprotonated Amino Acid Dimers. Phys. Chem. Chem. Phys. 2018, 20 (23), 15641-15652. https://doi.org/10.1039/c8cp01458b.

(36) Jackson, S. N.; Moyer, S. C.; Woods, A. S. The Role of Phosphorylated Residues in PeptidePeptide Noncovalent Complexes Formation. J. Am. Soc. Mass Spectrom. 2008, 19 (10), 15351541. https://doi.org/10.1016/j.jasms.2008.06.023.

(37) Woods, A. S.; Jackson, S. N. How Adenylate Cyclase Choreographs the Pas de Deux of the Receptors Heteromerization Dance. Neuroscience 2013, 238, 335-344. https://doi.org/10.1016/j.neuroscience.2013.02.006.

(38) Alves, S.; Woods, A.; Delvolvé, A.; Tabet, J. C. Influence of Salt Bridge Interactions on the GasPhase Stability of DNA/peptide Complexes. Int. J. Mass Spectrom. 2008, 278 (2-3), 122-128. https://doi.org/10.1016/j.ijms.2008.04.023.

(39) Xu, Y.; Afonso, C.; Wen, R.; Tabet, J.-C. Investigation of Double-Stranded DNA/drug Interaction by ESI/FT ICR: Orientation of Dissociations Relates to Stabilizing Salt Bridges. J. Mass Spectrom. 2008, 43 (11), 1531-1544. https://doi.org/10.1002/jms.1430.

(40) Brahim, B.; Tabet, J.-C.; Alves, S. Positive and Negative Ion Mode Comparison for the Determination of DNA/peptide Noncovalent Binding Sites through the Formation Of "threeBody" noncovalent Fragment lons. Eur. J. Mass Spectrom. 2018, 24 (1), 168-177. https://doi.org/10.1177/1469066717735672.

(41) Darii, E.; Alves, S.; Gimbert, Y.; Perret, A.; Tabet, J.-C. Meaning and Consequence of the Coexistence of Competitive Hydrogen Bond/salt Forms on the Dissociation Orientation of NonCovalent Complexes. J. Chromatogr. B Analyt. Technol. Biomed. Life. Sci. 2017, 1047, 45-58. https://doi.org/10.1016/j.jchromb.2016.09.038.

(42) Muller, L.; Jackson, S. N.; Woods, A. S. ETD and Sequential ETD Localize the Residues Involved in D2-A2A Heteromerization. RSC Adv 2014, 4 (80), 42272-42277.

https://doi.org/10.1039/C4RA04757E.

(43) Laskin, J.; Yang, Z.; Woods, A. S. Competition between Covalent and Noncovalent Bond Cleavages in Dissociation of Phosphopeptide-Amine Complexes. Phys. Chem. Chem. Phys. 2011, 13 (15), 6936-6946. https://doi.org/10.1039/c1cp00029b.

(44) Marcsisin, S. R.; Engen, J. R. Hydrogen Exchange Mass Spectrometry: What Is It and What Can It Tell Us? Anal. Bioanal. Chem. 2010, 397 (3), 967-972. https://doi.org/10.1007/s00216-0103556-4.

(45) Konermann, L.; Pan, J.; Liu, Y.-H. Hydrogen Exchange Mass Spectrometry for Studying Protein Structure and Dynamics. Chem. Soc. Rev. 2011, 40 (3), 1224-1234. https://doi.org/10.1039/c0cs00113a.

(46) Kostyukevich, Y.; Kononikhin, A.; Popov, I.; Nikolaev, E. Analytical Description of the H/D Exchange Kinetic of Macromolecule. Anal. Chem. 2018, 90 (8), 5116-5121. https://doi.org/10.1021/acs.analchem.7b05151.

(47) Masson, G. R.; Burke, J. E.; Ahn, N. G.; Anand, G. S.; Borchers, C.; Brier, S.; Bou-Assaf, G. M.; Engen, J. R.; Englander, S. W.; Faber, J.; Garlish, R.; Griffin, P. R.; Gross, M. L.; Guttman, M.; Hamuro, Y.; Heck, A. J. R.; Houde, D.; lacob, R. E.; Jørgensen, T. J. D.; Kaltashov, I. A.; Klinman, J. P.; Konermann, L.; Man, P.; Mayne, L.; Pascal, B. D.; Reichmann, D.; Skehel, M.; Snijder, J.; Strutzenberg, T. S.; Underbakke, E. S.; Wagner, C.; Wales, T. E.; Walters, B. T.; Weis, D. D.; Wilson, D. J.; Wintrode, P. L.; Zhang, Z.; Zheng, J.; Schriemer, D. C.; Rand, K. D. Recommendations for Performing, Interpreting and Reporting Hydrogen Deuterium Exchange Mass Spectrometry (HDX-MS) Experiments. Nat. Methods 2019, 16 (7), 595-602. https://doi.org/10.1038/s41592-019-0459-y.

(48) Zhang, J.; Feng, E.; Li, W.; Sheng, H.; Milton, J. R.; Easterling, L. F.; Nash, J. J.; Kenttämaa, H. I. Studies of the Fragmentation Mechanisms of Deprotonated Lignin Model Compounds in 
Tandem Mass Spectrometry. Anal. Chem. 2020, 92 (17), 11895-11903.

https://doi.org/10.1021/acs.analchem.0c02275.

(49) Carulla, N.; Zhou, M.; Giralt, E.; Robinson, C. V.; Dobson, C. M. Structure and Intermolecular Dynamics of Aggregates Populated during Amyloid Fibril Formation Studied by

Hydrogen/deuterium Exchange. Acc. Chem. Res. 2010, 43 (8), 1072-1079.

https://doi.org/10.1021/ar9002784.

(50) Dayal, P. V.; Singh, H.; Busenlehner, L. S.; Ellis, H. R. Exposing the Alkanesulfonate Monooxygenase Protein-Protein Interaction Sites. Biochemistry (Mosc.) 2015, 54 (51), 75317538. https://doi.org/10.1021/acs.biochem.5b00935.

(51) Zhang, Z.; Vachet, R. W. Kinetics of Protein Complex Dissociation Studied by Hydrogen/Deuterium Exchange and Mass Spectrometry. Anal. Chem. 2015, 87 (23), 1177711783. https://doi.org/10.1021/acs.analchem.5b03123.

(52) Modzel, M.; Stefanowicz, P.; Szewczuk, Z. Hydrogen Scrambling in Non-Covalent Complexes of Peptides. Rapid Commun. Mass Spectrom. 2012, 26 (23), 2739-2744.

https://doi.org/10.1002/rcm.6396.

(53) Guo, M.; Wu, H.; Yang, M.; Luo, Z. Acetone Dimer Hydrogenation under Vacuum Ultraviolet: An Intracluster Trimolecular Dissociation Mechanism. J. Phys. Chem. A 2019, 123 (50), 1073910745. https://doi.org/10.1021/acs.jpca.9b08833.

(54) Nikolić, D.; Macias, C.; Lankin, D. C.; van Breemen, R. B. Collision-Induced Dissociation of Phenethylamides: Role of Ion-Neutral Complexes. Rapid Commun. Mass Spectrom. 2017, 31 (17), 1385-1395. https://doi.org/10.1002/rcm.7915.

(55) Kuck, D. Scrambling versus Specific Processes in Gaseous Organic lons during Mass Spectrometric Fragmentation: Elucidation of Mechanistic Origins by Isotope Labelling - an Overview. J. Label. Compd. Radiopharm. 2007, 50 (5-6), 360-365. https://doi.org/10.1002/jlcr.1405.

(56) Olsen, J. V.; Macek, B.; Lange, O.; Makarov, A.; Horning, S.; Mann, M. Higher-Energy C-Trap Dissociation for Peptide Modification Analysis. Nat. Methods 2007, 4 (9), 709-712. https://doi.org/10.1038/nmeth1060.

(57) Frisch, M. J.; Trucks, G. W.; Schlegel, H. B.; Scuseria, G. E.; Robb, M. A.; Cheeseman, J. R.; Scalmani, G.; Barone, V.; Mennucci, B.; Petersson, G. A.; Nakatsuji, H.; Caricato, M.; Li, X.; Hratchian, H. P.; Izmaylov, A. F. ; Bloino, J. ; Zheng, G. ; Sonnenberg, J. L. ; Hada, M. ; Ehara, M. ; Toyota, K. ; Fukuda, R. ; Hasegawa, J. ; Ishida, M. ; Nakajima, T. ; Honda, Y. ; Kitao, O. ; Nakai, H. ; Vreven, T. ; Montgomery, Jr., J. A. ; Peralta, J. E. ; Ogliaro, F. ; Bearpark, M. ; Heyd, J. J. ; Brothers, E. ; Kudin, K. N. ; Staroverov, V. N. ; Kobayashi, R. ; Normand, J. ; Raghavachari, K. ; Rendell, A. ; Burant, J. C. ; Iyengar, S. S. ; Tomasi, J. ; Cossi, M. ; Rega, N. ; Millam, J. M. ; Klene, M. ; Knox, J. E. ; Cross, J. B. ; Bakken, V. ; Adamo, C. ; Jaramillo, J. ; Gomperts, R. ; Stratmann, R. E. ; Yazyev, O. ; Austin, A. J. ; Cammi, R. ; Pomelli, C. ; Ochterski, J. W. ; Martin, R. L. ; Morokuma, K. ; Zakrzewski, V. G. ; Voth, G. A. ; Salvador, P. ; Dannenberg, J. J. ; Dapprich, S. ; Daniels, A. D. ; Farkas, Ö. ; Foresman, J. B. ; Ortiz, J. V. ; Cioslowski, J. ; Fox, D.J. Gaussian 09, Revision D.01; Gaussian Inc. Wallingford CT 2009.

(58) Becke, A. D. Density-functional Thermochemistry. III. The Role of Exact Exchange. J. Chem. Phys. 1993, 98 (7), 5648-5652. https://doi.org/10.1063/1.464913.

(59) Stephens, P. J.; Devlin, F. J.; Chabalowski, C. F.; Frisch, M. J. Ab Initio Calculation of Vibrational Absorption and Circular Dichroism Spectra Using Density Functional Force Fields. J. Phys. Chem. 1994, 98 (45), 11623-11627. https://doi.org/10.1021/j100096a001.

(60) Geiger, T.; Cox, J.; Mann, M. Proteomics on an Orbitrap Benchtop Mass Spectrometer Using AllIon Fragmentation. Mol. Cell. Proteomics 2010, 9 (10), 2252-2261. https://doi.org/10.1074/mcp.M110.001537.

(61) Cooks, R. G.; Kaiser, R. E. Quadrupole Ion Trap Mass Spectrometry. Acc. Chem. Res. 1990, 23 (7), 213-219. https://doi.org/10.1021/ar00175a002. 
(62) March, R. E. An Introduction to Quadrupole Ion Trap Mass Spectrometry. J. Mass Spectrom. 1997, 32 (4), 351-369. https://doi.org/10.1002/(SICI)1096-9888(199704)32:4<351::AIDJMS512>3.0.CO;2-Y.

(63) Todd, J. F. .; March, R. E. A Retrospective Review of the Development and Application of the Quadrupole Ion Trap prior to the Appearance of Commercial Instruments. Int. J. Mass Spectrom. 1999, 190-191, 9-35. https://doi.org/10.1016/S1387-3806(99)00065-2.

(64) Fetterolf, D. D.; Yost, R. A. Energy-Resolved Collision-Induced Dissociation in Tandem Mass Spectrometry. Int. J. Mass Spectrom. Ion Phys. 1982, 44 (1-2), 37-50. https://doi.org/10.1016/0020-7381(82)80037-5.

(65) Wysocki, V. H.; Kenttämaa, H. I.; Cooks, R. G. Internal Energy Distributions of Isolated lons after Activation by Various Methods. Int. J. Mass Spectrom. Ion Process. 1987, 75 (2), 181-208. https://doi.org/10.1016/0168-1176(87)83054-9.

(66) Lopez, L. L.; Tiller, P. R.; Senko, M. W.; Schwartz, J. C. Automated Strategies for Obtaining Standardized Collisionally Induced Dissociation Spectra on a Benchtop Ion Trap Mass Spectrometer. Rapid Commun. Mass Spectrom. 1999, 13 (8), 663-668. https://doi.org/10.1002/(SICI)1097-0231(19990430)13:8<663::AID-RCM538>3.0.CO;2-H.

(67) Maquestiau, A.; Flammang, R. Studies of Prototropy by Mass Spectrometric Methods. Mass Spectrom. Rev. 1982, 1 (3), 237-255. https://doi.org/10.1002/mas.1280010303.

(68) Raczyńska, E. D.; Gal, J.-F.; Maria, P.-C. The Guanylated Bioamine Agmatine - A Theoretical Investigation of Its Structure and Exceptional High Basicity in the Gas Phase. Comput. Theor. Chem. 2017, 1109, 10-18. https://doi.org/10.1016/j.comptc.2017.03.032.

(69) Murray, K. K.; Boyd, R. K.; Eberlin, M. N.; Langley, G. J.; Li, L.; Naito, Y. Definitions of Terms Relating to Mass Spectrometry (IUPAC Recommendations 2013). Pure Appl. Chem. 2013, 85 (7), 1515-1609. https://doi.org/10.1351/PAC-REC-06-04-06.

(70) Damont, A.; Olivier, M.-F.; Warnet, A.; Lyan, B.; Pujos-Guillot, E.; Jamin, E. L.; Debrauwer, L.; Bernillon, S.; Junot, C.; Tabet, J.-C.; Fenaille, F. Proposal for a Chemically Consistent Way to Annotate lons Arising from the Analysis of Reference Compounds under ESI Conditions: A Prerequisite to Proper Mass Spectral Database Constitution in Metabolomics. J. Mass Spectrom. 2019, 54 (6), 567-582. https://doi.org/10.1002/jms.4372.

(71) Gao, H.; Chen, Y.; Leary, J. A. Kinetic Measurements of Phosphoglucose Isomerase and Phosphomannose Isomerase by Direct Analysis of Phosphorylated Aldose-ketose Isomers Using Tandem Mass Spectrometry. Int. J. Mass Spectrom. 2005, 240 (3), 291-299. https://doi.org/10.1016/j.ijms.2004.09.017.

(72) Antonio, C.; Larson, T.; Gilday, A.; Graham, I.; Bergström, E.; Thomas-Oates, J. Quantification of Sugars and Sugar Phosphates in Arabidopsis Thaliana Tissues Using Porous Graphitic Carbon Liquid Chromatography-Electrospray Ionization Mass Spectrometry. J. Chromatogr. A 2007, 1172 (2), 170-178. https://doi.org/10.1016/j.chroma.2007.10.011.

(73) Gao, H.; Petzold, C. J.; Leavell, M. D.; Leary, J. A. Investigation of Ion/molecule Reactions as a Quantification Method for Phosphorylated Positional Isomers. an FT-ICR Approach. J. Am. Soc. Mass Spectrom. 2003, 14 (8), 916-924. https://doi.org/10.1016/S1044-0305(03)00401-X.

(74) Drayß, M. K.; Blunk, D.; Oomens, J.; Polfer, N.; Schmuck, C.; Gao, B.; Wyttenbach, T.; Bowers, M. T.; Schäfer, M. Gas-Phase Structures of Solution-Phase Zwitterions: Charge Solvation or Salt Bridge? Int. J. Mass Spectrom. 2009, 281 (1-2), 97-100. https://doi.org/10.1016/j.ijms.2008.12.011.

(75) McLuckey, S. A.; Goeringer, D. E. Slow Heating Methods in Tandem Mass Spectrometry. J. Mass Spectrom. 1997, 32 (5), 461-474. https://doi.org/10.1002/(SICI)10969888(199705)32:5<461::AID-JMS515>3.0.CO;2-H.

(76) Gabelica, V.; De Pauw, E. Comparison of the Collision-Induced Dissociation of Duplex DNA at Different Collision Regimes: Evidence for a Multistep Dissociation Mechanism. J. Am. Soc. Mass Spectrom. 2002, 13 (1), 91-98. https://doi.org/10.1016/s1044-0305(01)00335-x.

(77) Zhang, H.-M.; Bou-Assaf, G. M.; Emmett, M. R.; Marshall, A. G. Fast Reversed-Phase Liquid Chromatography to Reduce Back Exchange and Increase Throughput in H/D Exchange 
Monitored by FT-ICR Mass Spectrometry. J. Am. Soc. Mass Spectrom. 2009, 20 (3), 520-524. https://doi.org/10.1016/j.jasms.2008.11.010.

(78) Rand, K. D.; Lund, F. W.; Amon, S.; Jørgensen, T. J. D. Investigation of Amide Hydrogen BackExchange in Asp and His Repeats Measured by Hydrogen $(1 \mathrm{H} / 2 \mathrm{H})$ Exchange Mass Spectrometry. Int. J. Mass Spectrom. 2011, 302 (1-3), 110-115. https://doi.org/10.1016/j.ijms.2010.08.027.

(79) Zhang, Z.; Zhang, A.; Xiao, G. Improved Protein Hydrogen/deuterium Exchange Mass Spectrometry Platform with Fully Automated Data Processing. Anal. Chem. 2012, 84 (11), 49424949. https://doi.org/10.1021/ac300535r.

(80) Schenk, E. R.; Almeida, R.; Miksovska, J.; Ridgeway, M. E.; Park, M. A.; Fernandez-Lima, F. Kinetic Intermediates of Holo- and Apo-Myoglobin Studied Using HDX-TIMS-MS and Molecular Dynamic Simulations. J. Am. Soc. Mass Spectrom. 2015, 26 (4), 555-563. https://doi.org/10.1007/s13361-014-1067-9.

(81) Molano-Arevalo, J. C.; Jeanne Dit Fouque, K.; Pham, K.; Miksovska, J.; Ridgeway, M. E.; Park, M. A.; Fernandez-Lima, F. Characterization of Intramolecular Interactions of Cytochrome c Using Hydrogen-Deuterium Exchange-Trapped Ion Mobility Spectrometry-Mass Spectrometry and Molecular Dynamics. Anal. Chem. 2017, 89 (17), 8757-8765.

https://doi.org/10.1021/acs.analchem.7b00844.

(82) K. Levsen: Fundamental Aspects in Organic Mass Spectrometry. Vol. 4 Der Reihe: Progress in Mass Spectrometry, Verlag Chemie, Weinheim, New York 1978. Berichte Bunsenges. Für Phys. Chem. 1978, 82 (10), 1121-1121. https://doi.org/10.1002/bbpc.19780821034.

(83) Xia, H.; Attygalle, A. B. Untrapping Kinetically Trapped lons: The Role of Water Vapor and lonSource Activation Conditions on the Gas-Phase Protomer Ratio of Benzocaine Revealed by lonMobility Mass Spectrometry. J. Am. Soc. Mass Spectrom. 2017, 28 (12), 2580-2587. https://doi.org/10.1007/s13361-017-1806-9.

(84) Range, K.; Riccardi, D.; Cui, Q.; Elstner, M.; York, D. M. Benchmark Calculations of Proton Affinities and Gas-Phase Basicities of Molecules Important in the Study of Biological Phosphoryl Transfer. Phys. Chem. Chem. Phys. 2005, 7 (16), 3070-3079. https://doi.org/10.1039/b504941e.

(85) Kinter, M. T.; Bursey, M. M. Ion/molecule Reactions of Ammonia with Two Translationally Excited C2H5O+ Isomers. J. Am. Chem. Soc. 1986, 108 (8), 1797-1801. https://doi.org/10.1021/ja00268a015.

(86) Liere, P.; Steiner, V.; Jennings, K. R.; March, R. E.; Tabet, J. C. Influence of Ion Activation and Thermalization Effects on Reaction Rate Constants in a Quadrupole Ion Trap Mass Spectrometer. Int. J. Mass Spectrom. Ion Process. 1997, 167-168, 735-751. https://doi.org/10.1016/S0168-1176(97)82067-8.

(87) Meot-Ner, M. Hyperconjugation: Equilibrium Secondary Isotope Effect on the Stability of the Tert-Butyl Cation. Kinetics of near-Thermoneutral Hydride Transfer. J. Am. Chem. Soc. 1987, 109 (26), 7947-7950. https://doi.org/10.1021/ja00260a003.

(88) Crestoni, M. E.; Fornarini, S.; Lentini, M.; Speranza, M. Hydride-Transfer Reactions in the Gas Phase. $2 .{ }^{1}$ Anchimeric Assistance in the $\mathrm{H}^{-}$Transfer from 1,1-Dimethylcyclopentane to Alkyl Cations. J. Phys. Chem. 1996, 100 (20), 8285-8294. https://doi.org/10.1021/jp952728I.

(89) Gronert, S.; Keeffe, J. R. Identity Hydride-Ion Transfer from C-H Donors to C Acceptor Sites. Enthalpies of Hydride Addition and Enthalpies of Activation. Comparison with C...H...C Proton Transfer. An Ab Initio Study. J. Am. Chem. Soc. 2005, 127 (7), 2324-2333. https://doi.org/10.1021/ja044002l.

(90) Wu, X.-N.; Zhao, H.-T.; Li, J.; Schlangen, M.; Schwarz, H. Highly Regioselective Hydride Transfer, Oxidative Dehydrogenation, and Hydrogen-Atom Abstraction in the Thermal Gas-Phase Chemistry of $[\mathrm{Zn}(\mathrm{OH})](+) / \mathrm{C} 3 \mathrm{H} 8$. Phys. Chem. Chem. Phys. 2014, 16 (48), 26617-26623. https://doi.org/10.1039/c4cp02139h.

(91) Zavras, A.; Ghari, H.; Ariafard, A.; Canty, A. J.; O'Hair, R. A. J. Gas-Phase lon-Molecule Reactions of Copper Hydride Anions [CuH2]- and [Cu2H3]. Inorg. Chem. 2017, 56 (5), 2387-2399. https://doi.org/10.1021/acs.inorgchem.6b02145. 
(92) Bouchoux, G. From the Mobile Proton to Wandering Hydride lon: Mechanistic Aspects of GasPhase Ion Chemistry. J. Mass Spectrom. 2013, 48 (4), 505-518.

https://doi.org/10.1002/jms.3204.

(93) Chai, Y.; Shao, Y.; Wang, L.; Wang, L. Loss of Benzaldehyde in the Fragmentation of Protonated Benzoylamines: Benzoyl Cation as a Hydride Acceptor in the Gas Phase. J. Mass Spectrom. 2017, 52 (10), 664-671. https://doi.org/10.1002/jms.3969.

(94) Cole, R. B.; Tabet, J. C.; Salles, C.; Jallageas, J. C.; Crouzet, J. Structural "memory Effects" Influencing Decompositions of Glucose Alkoxide Anions Produced from Monoterpene Glycoside Isomers in Tandem Mass Spectrometry. Rapid Commun. Mass Spectrom. 1989, 3 (3), 59-61. https://doi.org/10.1002/rcm.1290030302.

(95) Gaumann, T.; Stahl, D.; Tabet, J. C. The Mechanism of the Loss of H2 and H2O from 1,4Cyclohexanediol Anion and Related Compounds. Org Mass Spectrom 1983, 18 (6), 263-267.

(96) Tabet, J. C.; Hanna, I.; Fretizon, M. Stereospecific Hydride Transfer under NCl/OH- Conditions. Org Mass Spectrom 1985, 20 (1), 61-64.

(97) Afonso, C.; Cole, R. B.; Tabet, J.-C. Dissociation of Even-Electron Ions. In Electrospray and MALDI Mass Spectrometry; Cole, R. B., Ed.; John Wiley \& Sons, Inc.: Hoboken, NJ, USA, 2012; pp 631682.

(98) Schaaff, T. G.; Stephenson, J. L.; McLuckey, S. A. Gas Phase H/D Exchange Kinetics: DI versus D2O. J. Am. Soc. Mass Spectrom. 2000, 11 (2), 167-171. https://doi.org/10.1016/S10440305(99)00137-3.

(99) Wyttenbach, T.; Paizs, B.; Barran, P.; Breci, L.; Liu, D.; Suhai, S.; Wysocki, V. H.; Bowers, M. T. The Effect of the Initial Water of Hydration on the Energetics, Structures, and H/D Exchange Mechanism of a Family of Pentapeptides: An Experimental and Theoretical Study. J. Am. Chem. Soc. 2003, 125 (45), 13768-13775. https://doi.org/10.1021/ja037204a.

(100) Evans, S. E.; Lueck, N.; Marzluff, E. M. Gas Phase Hydrogen/deuterium Exchange of Proteins in an Ion Trap Mass Spectrometer. Int. J. Mass Spectrom. 2003, 222 (1-3), 175-187. https://doi.org/10.1016/S1387-3806(02)00948-X.

(101) Arrington, J. V.; Straus, R. N.; Reynolds, P. F.; Poutsma, J. L.; Marzluff, E. M.; Poutsma, J. C. Gas-Phase Hydrogen Deuterium Exchange Behavior of Lysine and Its Homologs. Int. J. Mass Spectrom. 2012, 330-332, 200-206. https://doi.org/10.1016/j.ijms.2012.07.018.

(102) Rajabi, K. Microsecond Pulsed Hydrogen/deuterium Exchange of Electrosprayed Ubiquitin Ions Stored in a Linear Ion Trap. Phys. Chem. Chem. Phys. 2015, 17 (5), 3607-3616. https://doi.org/10.1039/c4cp04716h.

(103) Lias, S. G.; Liebman, J. F.; Holmes, J. L.; Levin, R. D.; Mallard, W. G. Ion Energetics Data. In NIST Chemistry WebBook, NIST Standard Reference Database Number 69; Mallard W.G., Linstrom P.J. (Eds.): National Institute of Standards and Technology, Gaithersburg, MD, 2000.

(104) Navarro, G.; Ferré, S.; Cordomi, A.; Moreno, E.; Mallol, J.; Casadó, V.; Cortés, A.; Hoffmann, H.; Ortiz, J.; Canela, E. I.; Lluís, C.; Pardo, L.; Franco, R.; Woods, A. S. Interactions between Intracellular Domains as Key Determinants of the Quaternary Structure and Function of Receptor Heteromers. J. Biol. Chem. 2010, 285 (35), 27346-27359. https://doi.org/10.1074/jbc.M110.115634. 